\title{
Gasto público
} para impulsar el desarrollo económico e inclusivo y lograr los Objetivos de Desarrollo Sostenible 


\section{Gracias por su interés en esta publicación de la CEPAL}

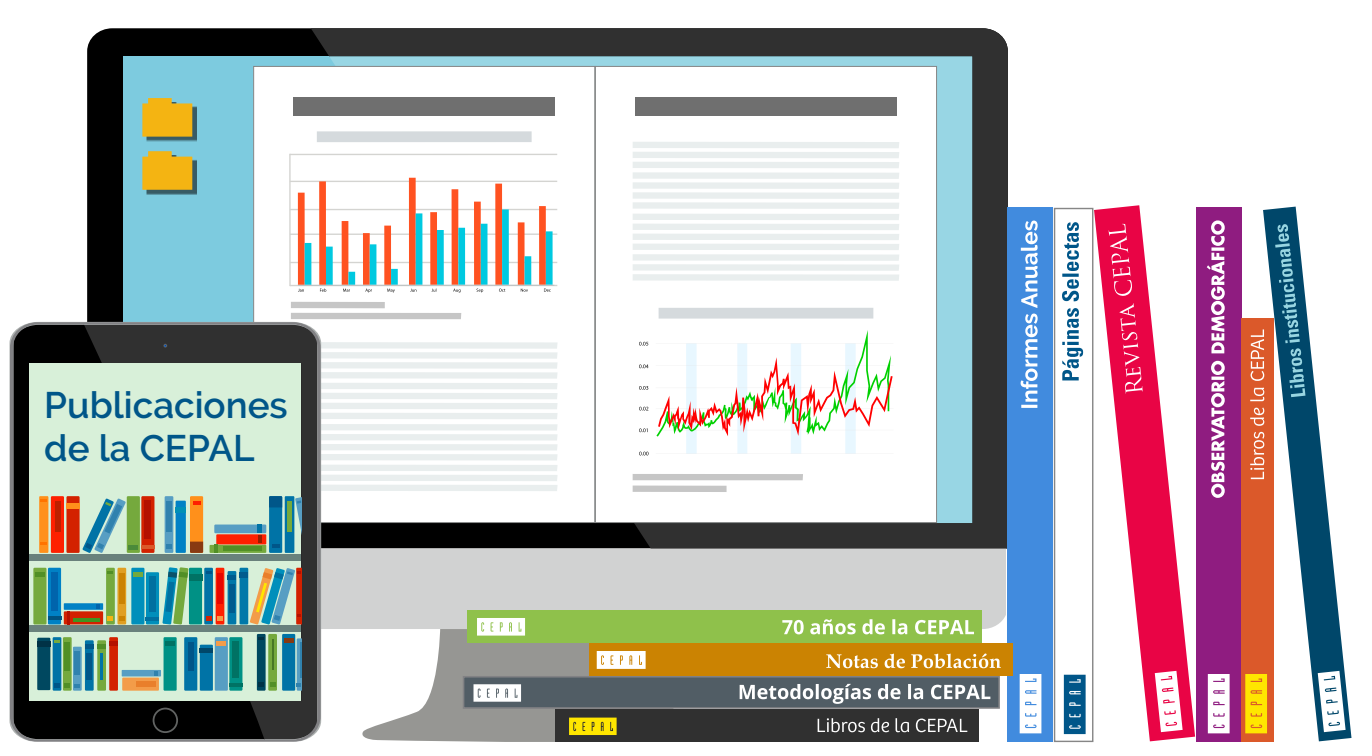

Si desea recibir información oportuna sobre nuestros productos editoriales y actividades, le invitamos a registrarse. Podrá definir sus áreas de interés y acceder a nuestros productos en otros formatos.

\section{Deseo registrarme}

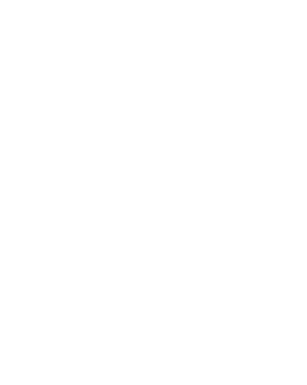

A www.cepal.org/es/publications

facebook.com/publicacionesdelacepal

P www.cepal.org/apps 
SERIE

\section{MACROECONOMÍA DEL DESARROLLO}

\section{Gasto público para impulsar el desarrollo económico e inclusivo y lograr los Objetivos de Desarrollo Sostenible}

Andrea Podestá 
Este documento fue preparado por Andrea Podestá, Consultora de la División de Desarrollo Económico de la Comisión Económica para América Latina y el Caribe (CEPAL), en el marco de la colaboración entre la CEPAL y la Agencia Española de Cooperación Internacional para el Desarrollo (AECID).

Las opiniones expresadas en este documento, que no ha sido sometido a revisión editorial, son de exclusiva responsabilidad de la autora y pueden no coincidir con las de la Organización.

Publicación de las Naciones Unidas

ISSN: 1680-8851 (versión electrónica)

ISSN: 1680-8843 (versión impresa)

LC/TS. 2020/123

Distribución: L

Copyright @ Naciones Unidas, 2020

Todos los derechos reservados

Impreso en Naciones Unidas, Santiago

S. $20-00670$

Esta publicación debe citarse como: A. Podestá, "Gasto público para impulsar el desarrollo económico e inclusivo y lograr los Objetivos de Desarrollo Sostenible", serie Macroeconomía del Desarrollo, No 214 (LC/TS.2020/123), Santiago, Comisión Económica para América Latina y el Caribe (CEPAL), 2020.

La autorización para reproducir total o parcialmente esta obra debe solicitarse a la Comisión Económica para América Latina y el Caribe (CEPAL), División de Publicaciones y Servicios Web, publicaciones.cepal@un.org. Los Estados Miembros de las Naciones Unidas y sus instituciones gubernamentales pueden reproducir esta obra sin autorización previa. Solo se les solicita que mencionen la fuente e informen a la CEPAL de tal reproducción. 


\section{Índice}

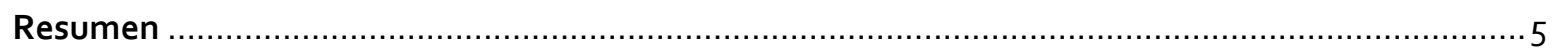

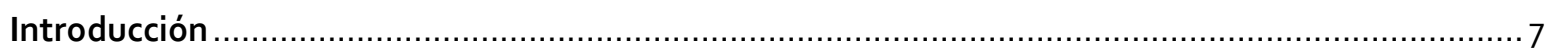

I. El papel del gasto público como herramienta para lograr los ODS $\ldots \ldots \ldots \ldots \ldots \ldots \ldots \ldots \ldots \ldots \ldots$

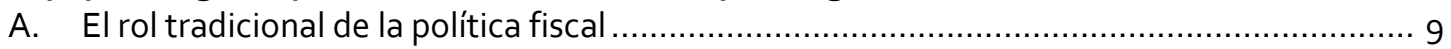

B. Breve revisión del marco conceptual de la medición del gasto público por funciones ........12

II. Panorama del gasto público según el propósito de las políticas en América Latina y el Caribe.

A. La composición y la evolución del gasto público funcional en la región..........................15

B. La evolución y asignación del gasto público por propósito en cada país..........................25

C. Análisis del vínculo entre la inversión pública y el gasto público funcional .......................34

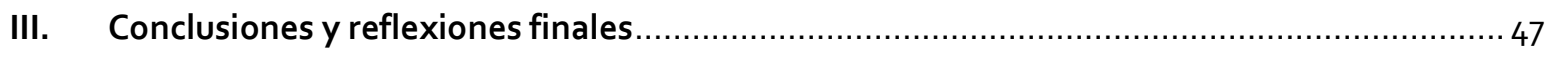

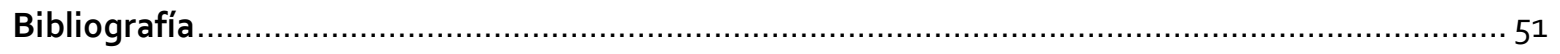

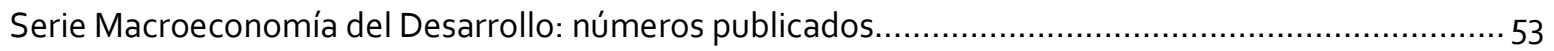

\section{Gráficos}

Gráfico 1 América Latina y el Caribe (16 países): gasto del gobierno central por subregión, 2000-2018 ............................................................................ 16

Gráfico 2 América Latina y el Caribe (16 países): gasto del gobierno central

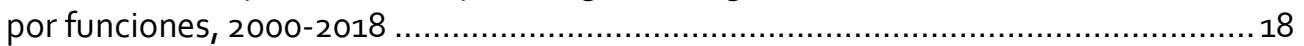

Gráfico 3 América Latina y el Caribe (16 países): evolución del gasto funcional del gobierno central por subperíodos, 2000-2018

Gráfico 4 América Latina y el Caribe (16 países): participación relativa del gasto del gobierno central por funciones, 2018 
Gráfico 5 América Latina y el Caribe (21 países): gasto del gobierno central por país y subregión, 200002008 y 2018.

Gráfico 6 América Latina y el Caribe (21 países): gasto del gobierno central por país y función, 200002008 y 2018

Gráfico 7 América Latina y el Caribe (21 países): distribución del gasto del gobierno central por función, 2018.

Gráfico 8 América Latina y el Caribe ( 16 países): gasto de capital y en asuntos económicos del gobierno central, 2000-2019

Gráfico 9 América Latina y el Caribe (16 países): gasto del gobierno central en asuntos económicos por grupo, 2000-2018.

Gráfico 10 América Latina y el Caribe (20 países): distribución del gasto en asuntos económicos del gobierno central por país y por grupo, 2018

Gráfico 11 América Latina y el Caribe (10 países): gasto del gobierno central según clasificación funcional y económica, 2018.

Gráfico 12 América Latina y el Caribe (10 países): gasto de capital del gobierno central por función, 2011-2018

Gráfico 13

Gráfico 14 América Latina (10 países): composición del gasto de capital según función del gobierno central y gasto máximo del período, por país, 2011-2018 América Latina (10 países): variación del gasto de capital según función del gobierno central, por país, 2011-2018

Gráfico 15 América Latina (10 países): variación del gasto de capital del gobierno central en asuntos económicos, por grupo y por país, 2011-2018

\section{Recuadros}

Recuadro 1

El gasto público según función de gobierno en coberturas institucionales más amplias 30

Recuadro 2 El gasto en salud en los países de América Latina y el Caribe .32

Recuadro 3 El gasto en asuntos económicos según subsector en coberturas institucionales más amplias 


\section{Resumen}

A los desafíos habituales de política fiscal que los países de América Latina y el Caribe deben enfrentar a fin de cumplir con los ODS se ha sumado la necesidad de implementar políticas activas para enfrentar la pandemia del COVID-19 y mitigar los efectos económicos, sanitarios y sociales que esta genera.

Un aporte importante para que los gobiernos tomen decisiones de política económica en este contexto es contribuir con mayor trasparencia e información fiscal. La revisión de las políticas de gasto público se ha convertido en un elemento clave que incide en varias dimensiones de los ODS. Contar con estadísticas actualizadas, detalladas y comparables entre los países sobre el nivel y la composición del gasto público según su clasificación funcional adquiere especial relevancia para identificar la intencionalidad de la política pública y evaluar si el destino de los recursos se encuentra en armonía con los objetivos acordados. Este tipo de análisis constituye una herramienta útil para que los países tomen decisiones de política focalizando los ingresos fiscales en las áreas del gasto público que sean más eficientes para lograr el desarrollo sostenible, erradicar la pobreza y reducir la desigualdad.

Es por ello que el presente documento analiza la evolución de las erogaciones públicas según el propósito de las políticas y examina de manera detallada cuáles han sido las prioridades del gasto durante los últimos años en los países de América Latina y el Caribe, con el fin de contribuir a fundamentar la discusión regional sobre el rol del Estado en el marco de la Agenda 2030. 



\section{Introducción}

A los desafíos habituales de política fiscal que los países de América Latina y el Caribe deben enfrentar a fin de cumplir con los Objetivos de la Agenda 2030 para el Desarrollo Sostenible ahora se suma la implementación de políticas activas para hacer frente a los retos que impone la pandemia de la enfermedad por coronavirus (COVID-19). Esta pandemia no solo afecta los sistemas sanitarios, el gasto público y la recaudación tributaria de los países, sino que tiene implicancias concretas en todos los ámbitos y repercute de forma significativa en la actividad económica, el empleo y la generación de ingresos familiares.

Estos retos son aún mayores en una región que se caracteriza por ser muy desigual y tener significativas brechas estructurales, sociales y económicas, que van desde una escasa productividad, una infraestructura deficiente, rezagos en la calidad de los servicios de salud y educación, persistentes brechas de género y desigualdades territoriales, hasta un impacto desproporcionado del cambio climático en los sectores más pobres de la sociedad ${ }^{1}$.

En este contexto de gran incertidumbre mundial, caída o desaceleración del crecimiento económico y aumento de las tasas de desempleo y la pobreza extrema, lograr los 17 Objetivos de Desarrollo Sostenible (ODS) representa un gran desafío y una oportunidad para los países de la región, que deben resguardar los avances logrados en la década anterior e instalarse en la senda del desarrollo sostenible e inclusivo. Al mismo tiempo, el inminente impacto de la pandemia en múltiples aspectos económicos y sociales hace que la acción del Estado a través de la política fiscal, en general, y de los programas de gasto público, en particular, cobre una importancia especial.

En los países de la región, los planes y estrategias nacionales se han ido alineando con la Agenda 2030, y en la mayoría se han establecido mecanismos institucionales de seguimiento y evaluación; no obstante, aún no se ha generado gran parte de la información estadística necesaria

1 Véase más información en CEPAL (2019e). 
para elaborar los indicadores que permitan evaluar el avance hacia las metas, dado que se requiere producir datos en áreas nuevas y con una mayor desagregación para centrar el análisis en los grupos más vulnerables².

En ese sentido, la revisión de las políticas de gasto público se convierte en un elemento clave que incide en varias dimensiones de los ODS. Contar con estadísticas actualizadas, detalladas y comparables entre los países sobre el nivel y la composición del gasto público según su clasificación funcional adquiere especial relevancia para identificar la intencionalidad de la política pública y evaluar si el destino de los recursos se encuentra en armonía con los objetivos acordados. Este tipo de análisis constituye una herramienta útil para que en los países se tomen decisiones de política que favorezcan los objetivos mencionados y se focalicen los ingresos fiscales en las áreas del gasto público que sean más eficientes para lograr el desarrollo sostenible, erradicar la pobreza y reducir la desigualdad.

Asimismo, en esta coyuntura especial debida a la pandemia del COVID-19, que implica una reducción de los ingresos tributarios, un menor acceso al financiamiento y una mayor presión sobre el gasto de los gobiernos, resulta fundamental saber a qué áreas se están destinando los recursos fiscales principalmente y acceder a estadísticas que se puedan comparar entre los países. Esto permitiría aportar una mayor transparencia sobre el uso de los recursos públicos, lo que es necesario para tomar decisiones en respuesta a esta crisis que afecta a toda la población, el crecimiento y el empleo.

Frente a este panorama, el objetivo de este documento es hacer un análisis detallado de las erogaciones públicas según el propósito de las políticas —una clasificación funcional del gasto- en los países de América Latina y el Caribe, para contribuir a fundamentar la discusión regional sobre el rol del Estado en el marco de la Agenda 2030.

Para cumplir con el objetivo planteado, luego de esta introducción, en la primera sección del estudio se analiza el papel del gasto público como instrumento para lograr los ODS, al tiempo que se examina el marco conceptual que se emplea al medir las erogaciones públicas. En la segunda sección se ofrece un panorama del gasto público según el propósito de las políticas en los países de la región, se analiza su composición y evolución, y se buscan similitudes y diferencias que fundamenten el análisis y el vínculo con el logro de los ODS. Al final de esa sección se examina la relación entre la inversión pública y el gasto público funcional, con el objeto de identificar los sectores que se han visto afectados por la contracción del gasto de capital en los últimos años y determinar si existe algún patrón a nivel regional o subregional. En la tercera y última sección se presentan una serie de conclusiones y reflexiones finales.

Véase un análisis sobre los avances y las limitaciones relacionados con la implementación de la Agenda 2030 en los países de la región en CEPAL (2019a). 


\section{El papel del gasto público como herramienta para lograr los ODS}

\section{A. El rol tradicional de la política fiscal}

Tradicionalmente, el rol de la política fiscal se ha resumido en tres funciones que están interrelacionadas: la asignación de recursos, la distribución del ingreso y la estabilización de la economía ${ }^{3}$. La primera se refiere a suministrar con eficiencia los bienes y servicios públicos de forma de asignar mejor los recursos cuando existen fallas de mercado. En la segunda, la política fiscal tiene por objeto modificar la forma en que los bienes se distribuyen entre los miembros de una sociedad, ajustando la distribución del ingreso y la riqueza de las personas, las zonas geográficas, los sectores o los factores productivos, para alinearla a lo que la sociedad considera más justo o igualitario. En la tercera función se procuran atenuar las variaciones de los ciclos económicos, reducir la volatilidad de las variables macroeconómicas y contribuir al crecimiento económico, al empleo y a la estabilidad de los precios.

Para llevar a cabo estas funciones, que tienen gran incidencia en el logro de los Objetivos de la Agenda 2030, los principales instrumentos de política fiscal son el gasto público y el sistema tributario. El presente documento se centra en la contribución del primero de estos instrumentos, con especial énfasis en la importancia de la inversión pública y en el gasto público según el propósito de la política.

Además, si bien las tres funciones tradicionales de la política fiscal están relacionadas entre sí, el análisis de esta sección se focaliza en el vínculo entre la política fiscal, la inversión y el crecimiento económico.

Los modelos teóricos destinados a explicar los efectos de la política fiscal sobre el crecimiento económico son abundantes y ofrecen resultados contrapuestos, ya que van desde las teorías según las cuales los estímulos fiscales aumentan el consumo agregado, la demanda y, por lo tanto, el PIB

3 Para obtener más información, véanse Musgrave y Musgrave (1991), Buchanan y Musgrave (1999) y Stiglitz (2000). 
(como el modelo keynesiano y el neokeynesiano), hasta los que prevén un efecto nulo e incluso negativo (como los modelos neoclásicos). Los efectos que la política fiscal tendrá sobre el crecimiento según los diferentes modelos teóricos dependen del horizonte de tiempo considerado (corto, mediano o largo plazo), de los supuestos sobre el comportamiento de los agentes privados y de la credibilidad de las estrategias utilizadas, entre otras consideraciones. Por lo tanto, el impacto que puede tener un cambio en el gasto público sobre el crecimiento económico parece definirse de acuerdo con la evidencia empírica4 ${ }^{4}$.

En este sentido, en un trabajo reciente del Fondo Monetario Internacional (FMI) 5 se subraya que los hallazgos coinciden en demostrar que el tamaño del multiplicador del gasto público depende de los siguientes factores: i) la ubicación en el ciclo económico, pues el multiplicador es mayor en las recesiones que en las expansiones (Auerbach y Gorodnichenko, 2012 y 2013; Riera-Crichton, Vegh y Vuletin, 2015); ii) el régimen de tipo de cambio, que cuando es fijo da lugar a multiplicadores mayores (Ilzetzki, Mendoza y Végh, 2013); iii) el nivel de endeudamiento, que cuando es bajo da como resultado un multiplicador mayor (Ilzetzki, Mendoza y Végh, 2013; Huidrom y otros, 2019); iv) cuán acomodaticia es la política monetaria, ya que el multiplicador es mayor cuando la política monetaria es laxa o tiene tasas de interés cercanas a cero (Christiano, Eichenbaum y Rebelo, 2011; Coenen, Straub y Trabandt, 2013), y v) el grado de apertura de la economía, que cuando es más abierta al comercio internacional da lugar a multiplicadores más pequeños (Ilzetzki, Mendoza y Végh, 2013; González-García, Lemus y Mrkaic, 2013).

Por otra parte, en el caso particular de la inversión pública y de otras políticas fiscales destinadas a promover la inversión, su efectividad para incidir positivamente en el crecimiento de la economía depende de una serie de factores que deberían tenerse en cuenta, como el clima de inversión (dado por la calidad del marco institucional, las restricciones organizacionales, la seguridad jurídica y las regulaciones, entre otras), la volatilidad macroeconómica y el desarrollo financiero ${ }^{6}$.

Un aspecto que suele considerarse en la relación entre la política fiscal y la inversión se refiere a la complementariedad o la competencia entre la inversión pública y la privada. En el primer caso, la inversión pública en servicios públicos e infraestructura afecta de forma positiva la rentabilidad de la inversión privada, dado que reduce los costos privados de producción y puede aumentar la demanda y el uso de la capacidad instalada. La relación de complementariedad entre inversión pública e inversión privada se da sobre todo cuando la primera está destinada a la infraestructura y la educación. Por otro lado, la inversión pública puede competir con la privada en la obtención de financiamiento y de insumos productivos. En los países en vías de desarrollo, la competencia en el mercado financiero puede ser más importante debido a que la oferta de créditos es más restringida. Además, si el aumento de la inversión pública ocurre en un contexto de déficit fiscal, el incremento del endeudamiento público podría presionar al alza la tasa de interés y desplazar en cierta forma la inversión privada, lo que se conoce como efecto de desplazamiento ${ }^{7}$. Los datos empíricos disponibles sobre los países de América Latina y el Caribe apuntan más bien a la existencia de complementariedad, es decir, a una relación positiva entre la inversión pública y la privada, lo que muestra que la inversión pública en los países de la región genera externalidades positivas que incrementan la productividad global de las empresas y favorecen el crecimiento ${ }^{8}$.

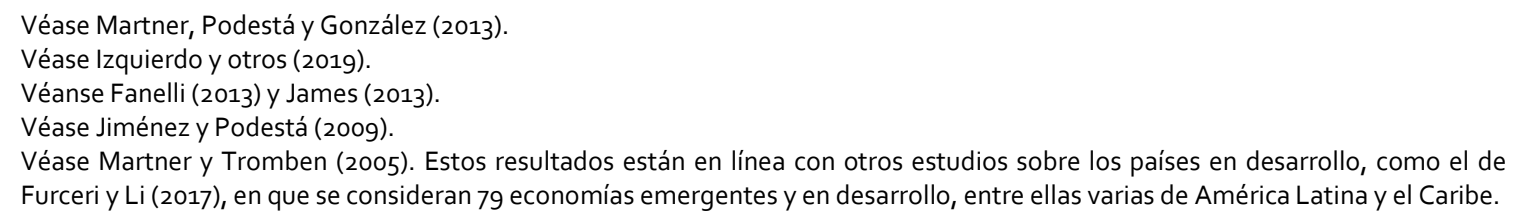


El resultado dominante de complementariedad también se observa en que las estimaciones sobre el efecto multiplicador del gasto público en el producto, tanto en los países desarrollados como en los países en desarrollo, son mayores cuando se trata de inversión pública que cuando se trata del gasto corriente primario. Esto refuerza el argumento de que la inversión pública aumenta la productividad marginal del capital privado y la mano de obra, y tiene un efecto positivo en la capacidad productiva de la economía, así como en la inversión y el consumo privados.

Por ejemplo, Riera-Crichton, Vegh y Vuletin (2015) estiman que, en 16 países de América Latina, el multiplicador acumulado del gasto de capital después de cinco años es 2,7 , lo que contrasta con el multiplicador de 1,6 que estiman en relación con el gasto corriente ${ }^{9}$. De manera similar, Izquierdo y otros (2019) llevan a cabo un análisis empírico a partir de una muestra de países europeos, estados de los Estados Unidos y provincias argentinas, y en los tres casos concluyen que el multiplicador de la inversión pública supera ampliamente el del gasto primario. También demuestran que los países, estados o provincias cuyo acervo inicial de capital público es bajo (como proporción del PIB) tienen multiplicadores de inversión pública significativamente más altos que los que tienen un acervo inicial alto. En el caso particular de las provincias de la Argentina, el multiplicador del gasto primario provincial es menor que uno $(0,56)$, mientras que el multiplicador de la inversión pública es bastante elevado $(1,60)$. No obstante, cuando el acervo inicial de capital público es alto, el multiplicador de la inversión pública es cercano a cero $(0,23)$, es decir, la inversión pública casi no afecta el producto; en cambio, dicho multiplicador alcanza un valor de 2,03 cuando el acervo inicial de capital público es bajo.

Los datos empíricos disponibles también muestran que los multiplicadores del gasto y la inversión pública son mayores cuando su eficiencia es alta (Furceri y Li, 2017; FMI, 2014a; Izquierdo y otros, 2019). Un aumento poco eficiente del gasto o la inversión pública podría no tener efectos positivos sobre el crecimiento económico, en tanto que las mejoras en la eficiencia de estos pueden conducir a una mayor actividad económica.

Dado el rol clave que la inversión pública desempeña en el crecimiento económico, la Comisión Económica para América Latina y el Caribe (CEPAL) ha hecho hincapié en la importancia de diseñar reglas fiscales dotadas de mecanismos anticíclicos eficientes que protejan el gasto público en capital y atenúen la volatilidad macroeconómica de la región. Los mecanismos que complementan las políticas anticíclicas con la protección y el estímulo de la inversión pública en la parte baja del ciclo pueden ser mucho más efectivos que las reglas fiscales basadas únicamente en metas de gasto o déficit. Si el gasto público de capital tiende a favorecer el crecimiento, ello generará ingresos tributarios en el futuro, contribuirá a la consolidación fiscal y puede ayudar a que se cree un círculo virtuoso de crecimiento sostenible ${ }^{10}$.

En definitiva, en los países de América Latina y el Caribe debería ser prioritario hacer un mayor esfuerzo en cuanto a la cantidad y la calidad de la inversión pública para seguir la ruta propuesta en la Agenda 2030, cerrar los diferentes tipos de brechas que existen en la región y orientar las políticas públicas hacia la sostenibilidad económica, social y ambiental. Es por ello que en la presente investigación se examina de manera detallada cuáles han sido las prioridades del gasto público, en general, y del gasto de capital, en particular, durante los últimos años en los países de la región.

9 Véase CEPAL (2018).

10 Véase CEPAL (2015 y 2018). 


\section{B. Breve revisión del marco conceptual de la medición del gasto público porfunciones}

En el Sistema de Cuentas Nacionales (SCN) 1993 se brindan cuatro clasificaciones de gastos por finalidad. Una de ellas es la clasificación de las funciones del gobierno (CFG) ${ }^{11}$, que permite examinar el gasto público destinado a funciones o finalidades determinadas y conocer el modo en que los gobiernos desempeñan funciones económicas y sociales; además, puede utilizarse para hacer comparaciones a lo largo del tiempo y entre los países ${ }^{12}$.

Según el Manual de Estadísticas de Finanzas Públicas 2014 (FMI, 2014b), la CFG es una clasificación detallada de las funciones u objetivos socioeconómicos que persiguen las unidades del gobierno general por medio de distintos tipos de gasto. Las funciones se clasifican en diez divisiones que luego se subdividen en grupos y clases. Las divisiones se refieren a los objetivos generales del gobierno, en tanto que los grupos y las clases corresponden a los medios a través de los cuales se alcanzan esos objetivos.

Las divisiones son las siguientes:

i) Servicios públicos generales. Incluye el gasto relacionado con la administración, la gestión o el apoyo de los órganos ejecutivos y legislativos, las erogaciones en asuntos financieros, fiscales y exteriores, la administración de la ayuda económica exterior, los gastos en servicios generales (administración y gestión de los servicios generales de personal, planificación y estadísticas), las transacciones de la deuda pública (pago de intereses y gastos por emisión de deuda) y las transferencias de carácter general entre diferentes niveles de gobierno.

ii) Defensa. Comprende las erogaciones en materia de defensa militar, defensa civil y ayuda militar al exterior.

iii) Orden público y seguridad. Abarca los servicios de policía, los servicios de protección contra incendios, los tribunales de justicia y la administración de las prisiones.

iv) Asuntos económicos. En esta división se contabiliza lo siguiente: el gasto en asuntos económicos, comerciales y laborales en general (incluida la administración, formulación y ejecución de políticas económicas, comerciales y laborales, su reglamentación y promoción, la supervisión de las condiciones de trabajo y los programas generales de empleo, entre otros); la administración de asuntos, servicios y diversos programas relacionados con la agricultura, la silvicultura, la pesca y la caza; el gasto en programas del sector de los combustibles (carbón, petróleo, gas natural, combustibles nucleares y otros) y la energía (eléctrica y no eléctrica); las erogaciones en asuntos, servicios y programas vinculados con la minería, las manufacturas y la construcción; los gastos relacionados con la explotación, la utilización, la construcción o el mantenimiento de sistemas e instalaciones de transporte (terrestre, marítimo, ferroviario y aéreo, así como los oleoductos, gasoductos y otros); los gastos concernientes a los sistemas de comunicación (postal, telefónica, telegráfica, inalámbrica y satelital), y las erogaciones en programas destinados a otros ramos (distribución, almacenamiento, depósito, hoteles, restaurantes, turismo y proyectos polivalentes de desarrollo).

11 Las otras tres clasificaciones son la clasificación del consumo individual por finalidades (CCIF), la clasificación de las finalidades de las instituciones sin fines de lucro que sirven a los hogares (CFISFL) y la clasificación de los gastos de los productores por finalidades (CGPF).

12 Véase Naciones Unidas (2002). 
v) Protección del medio ambiente. Comprende la ordenación de desechos (recogida, tratamiento y eliminación), la ordenación de aguas residuales (gestión del sistema de alcantarillado y tratamiento de aguas residuales), la reducción de la contaminación (actividades relacionadas con la protección del aire ambiente, el clima, el suelo y las aguas subterráneas, la reducción de los ruidos y las vibraciones, y la protección contra la radiación), así como la protección de la diversidad biológica y del paisaje (actividades relacionadas con la protección de la fauna, la flora y el hábitat).

vi) Vivienda y servicios comunitarios. Abarca las erogaciones en asuntos y servicios relacionados con la urbanización, la erradicación de asentamientos irregulares y la construcción de viviendas, así como los gastos que atañen al desarrollo comunitario y la planificación de comunidades, el abastecimiento de agua y el alumbrado público.

vii) Salud. Incluye las erogaciones en servicios prestados a particulares y en servicios prestados a colectivos. Se subdivide en los siguientes grupos: productos, útiles y equipos médicos (gasto en medicamentos, prótesis, útiles y equipos médicos y otros productos relacionados con la salud que se consumen fuera de las instalaciones o centros de salud); servicios para pacientes externos (servicios médicos, odontológicos y paramédicos prestados a pacientes que acuden a consultas externas); servicios hospitalarios (servicios de hospitales generales y especializados, hospitales militares, centros médicos, centros de maternidad, residencias de ancianos y de convalecencia, así como centros de rehabilitación que proporcionan servicios sobre todo a pacientes ingresados), y servicios de salud pública (gestión de bancos de sangre, diagnóstico y prevención de enfermedades, recopilación de datos epidemiológicos y servicios de planificación familiar, entre otros).

viii) Actividades recreativas, cultura y religión. Comprende la prestación de servicios recreativos, deportivos y culturales, y la gestión de instalaciones destinadas a esas actividades (campos de deportes, canchas, estadios, parques, playas, campings, bibliotecas, museos, galerías de arte, teatros, monumentos y otros), así como la administración, supervisión y regulación de los servicios de radio, televisión y editoriales, y el gasto relacionado con asuntos religiosos y otros servicios comunitarios.

ix) Educación. Abarca las erogaciones en servicios prestados a alumnos y estudiantes a título individual y las erogaciones en servicios colectivos. Los servicios docentes colectivos tienen que ver con la formulación y administración de la política del gobierno, el establecimiento y la aplicación de las normas, la regulación, autorización y supervisión de los centros de enseñanza, y la investigación aplicada. El gasto en educación se subdivide en los siguientes grupos: enseñanza preescolar y primaria; enseñanza secundaria; enseñanza postsecundaria no terciaria; enseñanza terciaria; enseñanza no atribuible a ningún nivel, y servicios auxiliares de la educación.

$x$ ) Protección social. Comprende las erogaciones en servicios y transferencias a personas y familias y las erogaciones en servicios proporcionados a colectivos. Los servicios colectivos de protección social se relacionan con la formulación y la administración de la política social, la formulación y la ejecución de la legislación y otras normas sobre cómo brindar protección social, y la investigación aplicada en protección social. Abarca los siguientes grupos: enfermedad $\mathrm{e}$ incapacidad (beneficios en efectivo o en especie por enfermedad o discapacidad, pago de licencia por enfermedad, pensiones por invalidez, servicios de cuidados a discapacitados, asistencia en las tareas diarias a personas enfermas, alojamiento para personas con discapacidad y otros); edad avanzada (prestaciones en efectivo y en especie para cubrir los riesgos relacionados con la vejez, como las pensiones de vejez y los servicios de cuidados, alojamiento y alimentos); sobrevivientes (prestaciones en efectivo y 
en especie a los sobrevivientes de una persona fallecida, como pensiones y gastos funerarios); familia e hijos (prestaciones en efectivo y en especie a familias con hijos a cargo, como asignaciones por maternidad y por hijos dependientes, pagos en caso de nacimiento, licencias por cuidado de los hijos, prestación de alojamiento, provisión de comida a niños en edad preescolar, servicios de cuidado infantil, gasto en orfanatos y familias de guarda, entre otros); desempleo (subsidios de desempleo, jubilación anticipada debido a desempleo, programas de capacitación para el empleo y provisión de alojamiento, alimentos o ropa a personas desempleadas y sus familias); vivienda (prestaciones en especie para ayudar a las familias vulnerables a sufragar el costo de una vivienda y a pagar alquileres, así como construcción de viviendas sociales), y otras políticas contra la exclusión social (prestaciones en efectivo y en especie a personas indigentes, inmigrantes, indígenas, refugiados, alcohólicos o toxicómanos, y a personas víctimas de actos criminales violentos, entre otros).

Asimismo, en cada una de las diez divisiones anteriores se incluye el gasto en investigación y desarrollo relacionado con esa categoría.

En cuanto a la cobertura institucional del nivel de gobierno para medir el gasto público, en el Manual de Estadísticas de Finanzas Públicas 2014 (FMI, 2014b) se distinguen los siguientes niveles:

- Gobierno central: su autoridad política abarca todo el territorio del país y suele estar compuesto por un gobierno central presupuestario, unidades extrapresupuestarias y fondos de seguridad social (a menos que en el país se utilice un subsector separado para estos fondos).

- Gobierno general: comprende tanto el gobierno central como los gobiernos subnacionales (gobiernos intermedios y locales) y la seguridad social.

- Sector público no financiero (SPNF): además del gobierno general, incluye las sociedades públicas no financieras, es decir, las entidades públicas cuya actividad principal consiste en producir bienes de mercado o servicios no financieros.

- Sector público: consta del SPNF y de las sociedades públicas financieras (como el banco central y los bancos comerciales públicos).

En este documento, el análisis de las tendencias del gasto público funcional en la región se hace, en primera instancia, a nivel de los gobiernos centrales de cada país, debido a que hay más datos disponibles sobre ellos y con el fin de mantener la coherencia con otros análisis publicados por la CEPAL, como es el caso del gasto público social. Sin embargo, en algunos países, como los que tienen una organización federal o un alto nivel de descentralización, el gasto que ejecutan los gobiernos intermedios y locales suele ser significativo, por lo que, cuando existe información disponible, se examina también una cobertura institucional más amplia, ya que es más representativa de la realidad (véase el recuadro 1). 


\section{Panorama del gasto público según el propósito de las políticas en América Latina y el Caribe}

\section{A. La composición y la evolución del gasto público funcional en la región}

A continuación, se presenta un análisis de las principales tendencias del gasto público según la clasificación de las funciones del gobierno en relación con 16 países de América Latina: el análisis abarca el gobierno central en el período 2000-2018 ${ }^{13}$. En los casos en que hay información disponible, en el recuadro 1 se complementa el análisis con una cobertura institucional más amplia, siguiendo los mismos criterios que se aplicaron en las últimas ediciones del Panorama Social de América Latina. Además, se examina la evolución y la composición del gasto según el propósito en cinco países del Caribe de habla inglesa respecto de los cuales había datos disponibles sobre el período 2008-2018: Bahamas, Barbados, Guyana, Jamaica y Trinidad y Tabago.

El gasto público promedio de 16 países latinoamericanos a nivel del gobierno central muestra una tendencia creciente en el período considerado, ya que pasó del $17,8 \%$ del PIB en 2000 al $20,7 \%$ del PIB en 2018, aunque en ese último año se aprecia una reducción frente al valor de 2017, que refleja el proceso de consolidación fiscal llevado a cabo en los países (véase el gráfico 1) ${ }^{14}$.

Como consecuencia de la crisis económica mundial de 2008-2009, en gran parte de los países de la región se implementaron políticas fiscales expansivas que tenían por objeto apuntalar la demanda agregada. Así, se aumentó el gasto en subsidios, transferencias y ciertos programas sociales que, si bien

13 Debido a la falta de datos desagregados por función de gobierno y actualizados respecto de toda la serie considerada, no se incluye información de Bolivia (Estado Plurinacional de), Cuba, Haití ni Venezuela (República Bolivariana de).

14 El nivel del gasto público según la clasificación funcional no necesariamente coincide con el de la clasificación económica del gasto publicado en otros documentos de CEPAL, debido sobre todo a que en algunos países la cobertura institucional no coincide por completo y a que la cantidad de países incluidos en el promedio no es la misma, entre otras consideraciones metodológicas. 
ayudaron a atenuar el impacto de la crisis sobre los sectores más vulnerables, en algunos casos dieron lugar a una suba permanente del gasto. Además, el incremento del pago de los intereses de la deuda en los últimos siete años incidió en la evolución del gasto.

\section{Gráfico 1}

América Latina y el Caribe (16 países): gasto del gobierno central por subregión, 2000-2018a (En porcentajes del PIB)

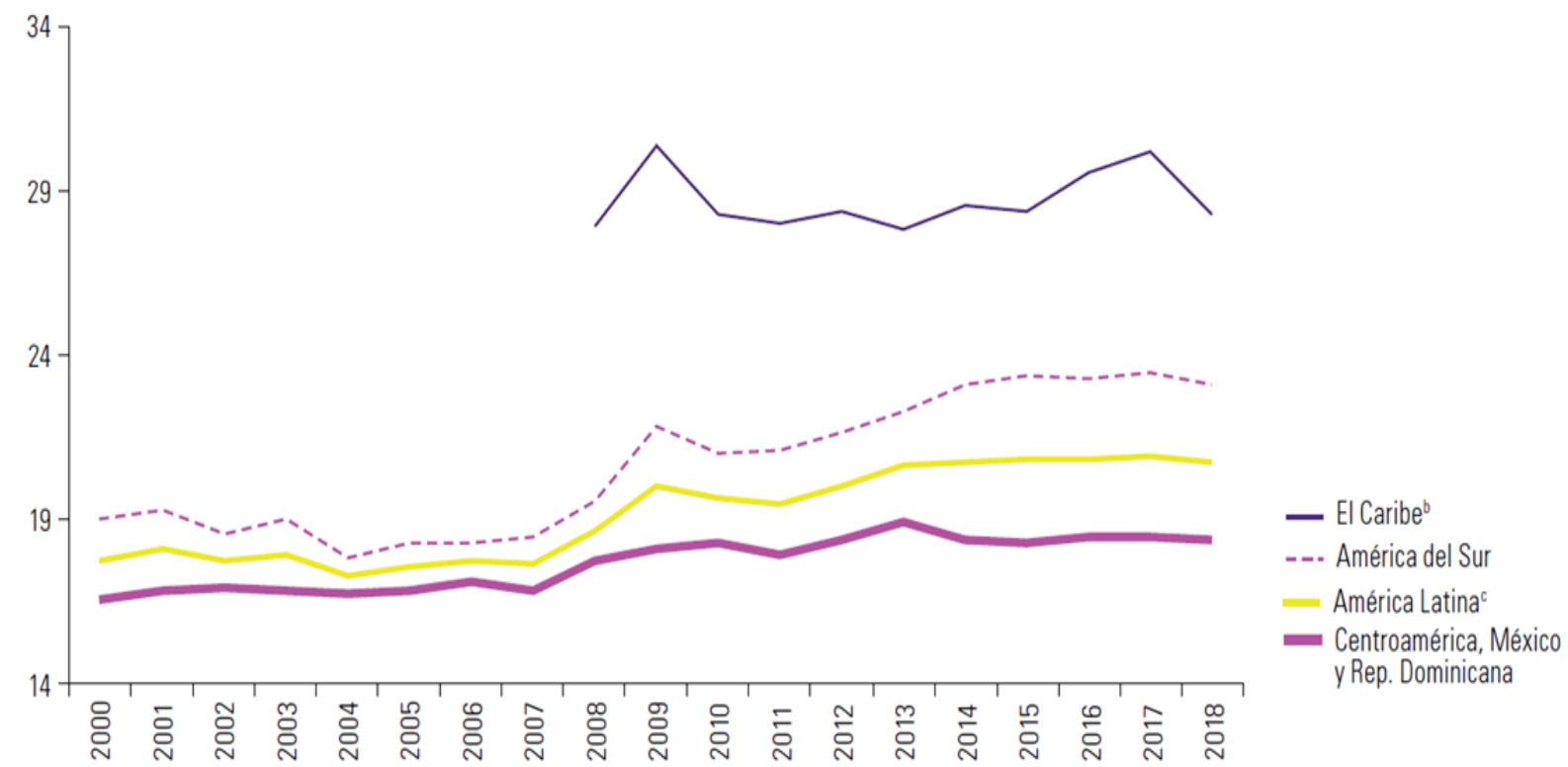

Fuente: Comisión Económica para América Latina y el Caribe (CEPAL), sobre la base de información oficial de los países.

${ }^{a}$ El nivel de gasto público que se presenta aquí según la clasificación funcional no necesariamente coincide con el de la clasificación económica del gasto publicado en otros documentos de la CEPAL.

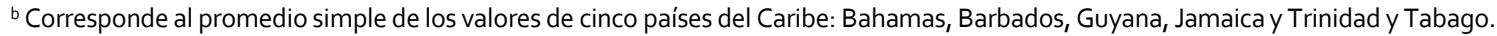

c Corresponde al promedio simple de los valores de 16 países: Argentina, Brasil, Chile, Colombia, Costa Rica, Ecuador, El Salvador, Guatemala, Honduras, México, Nicaragua, Panamá, Paraguay, Perú, República Dominicana y Uruguay. La cobertura del Perú corresponde al gobierno general.

Si bien la tendencia creciente del gasto del gobierno central se observa tanto en la subregión de América del Sur como en el grupo formado por los seis países de Centroamérica, México y la República Dominicana, en los países sudamericanos se parte de un nivel superior y se observa un mayor ritmo de crecimiento del gasto. El mayor dinamismo del gasto en esos países se explica, en parte, por el auge del precio de las materias primas de la década de 2000, que impulsó los ingresos fiscales en las economías que tenían grandes sectores exportadores de productos primarios y amplió la participación del gasto público en el PIB.

De esta forma, en 2018, el gasto promedio de los ocho países de América del Sur alcanza un 23,1\% del PIB, mientras que el gasto promedio en Centroamérica, México y la República Dominicana llega al $18,3 \%$ del PIB. Así, el gobierno central del primer grupo de países gasta en promedio casi 5 puntos del PIB más que el del segundo, brecha que a comienzos de siglo era de 2,5 puntos. Sin embargo, en los datos del gobierno central de la mayoría de los países que conforman el segundo grupo y en algunos de los que integran el primero no se incluye el gasto en seguridad social, ya que esos fondos se consideran como un subsector separado. 
En la muestra de cinco países del Caribe de habla inglesa, el promedio del gasto del gobierno central presenta, en general, un nivel estable en torno al $28 \%$ del PIB entre 2008 y 2018 , aunque con dos puntos máximos que llegan al 30\% del PIB en la gran recesión de 2009 y en 2017. Luego, en 2018 se aprecia una caída del gasto público al $28,2 \%$ del PIB como resultado de las políticas de consolidación de las cuentas fiscales implementadas en esos países. Este nivel se encuentra por encima de los valores promedios de las otras dos subregiones analizadas.

Con el fin de evaluar a qué tipo de políticas los gobiernos de la región han destinado principalmente los recursos y cuáles han sido las áreas que explican el incremento del gasto público, se examina la composición de este de acuerdo con la clasificación de las funciones del gobierno: esto permitirá examinar las prioridades del suministro de bienes y servicios públicos, así como el cambio de estas a lo largo del tiempo (véanse los gráficos 2 y 3 ).

El aumento del gasto ejecutado por los gobiernos centrales en la muestra de 16 países de América Latina se explica por las mayores erogaciones destinadas a financiar políticas sociales, en particular en las áreas de salud, educación y protección social ${ }^{15}$. El gasto promedio de los países de América Latina en estas funciones pasó de representar el $1,5 \%$, el $2,9 \%$ y el $3,2 \%$ del PIB en 2000 , a representar el $2,3 \%$, el $3,9 \%$ y el $4,0 \%$ del PIB en 2018 , respectivamente (véase el gráfico $2 \mathrm{~A}$ ). En la función de protección social se incluyen, entre otros programas, el pago de pensiones y los programas de transferencias condicionadas, que crecieron en las últimas décadas. El incremento del gasto en estas tres áreas se vincula a una mayor cobertura en educación (sobre todo en el nivel secundario, dado que las tasas de cobertura en el nivel primario ya eran relativamente altas en el siglo pasado), así como en salud y en previsión social, donde se destaca un crecimiento de las pensiones tanto contributivas como no contributivas (véase el gráfico $3 \mathrm{~A}$ ).

El gasto en servicios públicos generales, que incluye los intereses de la deuda pública, había mostrado una tendencia decreciente entre 2004 y 2012, para luego manifestar un comportamiento al alza en concordancia con el mayor endeudamiento de la región: en 2018 alcanzó un valor similar al de comienzo de siglo ( $5 \%$ del PIB) (véase gráfico $2 \mathrm{~A}$ ). La contracara de esa dinámica es la evolución de los recursos destinados a la función de asuntos económicos, que se caracteriza por comprender gran parte de la inversión pública y que muestra la evolución opuesta: un aumento entre 2003 y 2013 y una disminución a partir de ese año. Así, el gasto en funciones económicas se redujo desde casi el 3\% del PIB en 2013 al 2\% del PIB en 2018, último año disponible para el análisis funcional del gasto en la región. Un comportamiento similar se da en el caso del gasto en vivienda y servicios comunitarios, que también tiene un componente importante de inversión pública (véase gráfico $3 \mathrm{~A}$ ).

El gasto en defensa y el gasto en orden público y seguridad reflejan una dinámica contrapuesta entre sí. Mientras que en el primer caso se observa una tendencia decreciente durante el período analizado, en el segundo se observa un crecimiento del 1,3\% del PIB en 2000 al 1,8\% del PIB en 2018 (véase gráfico $3 \mathrm{~A}$ ).

15 Véase un análisis detallado sobre el gasto social en los países de la región en CEPAL (2019b). 


\section{Gráfico 2}

América Latina y el Caribe (16 países) ${ }^{\mathrm{a}}$ : gasto del gobierno central por funciones, 2000-2018 (En porcentajes del PIB)

A. América Latina (16 países)

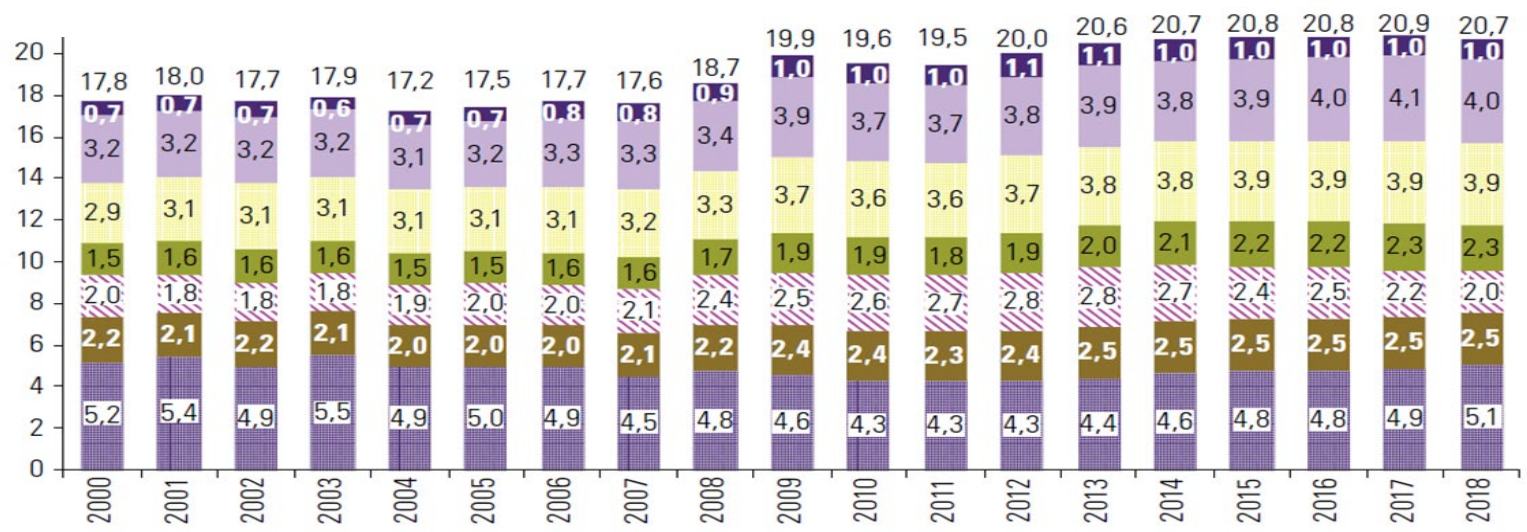

B. América del Sur (8 países)

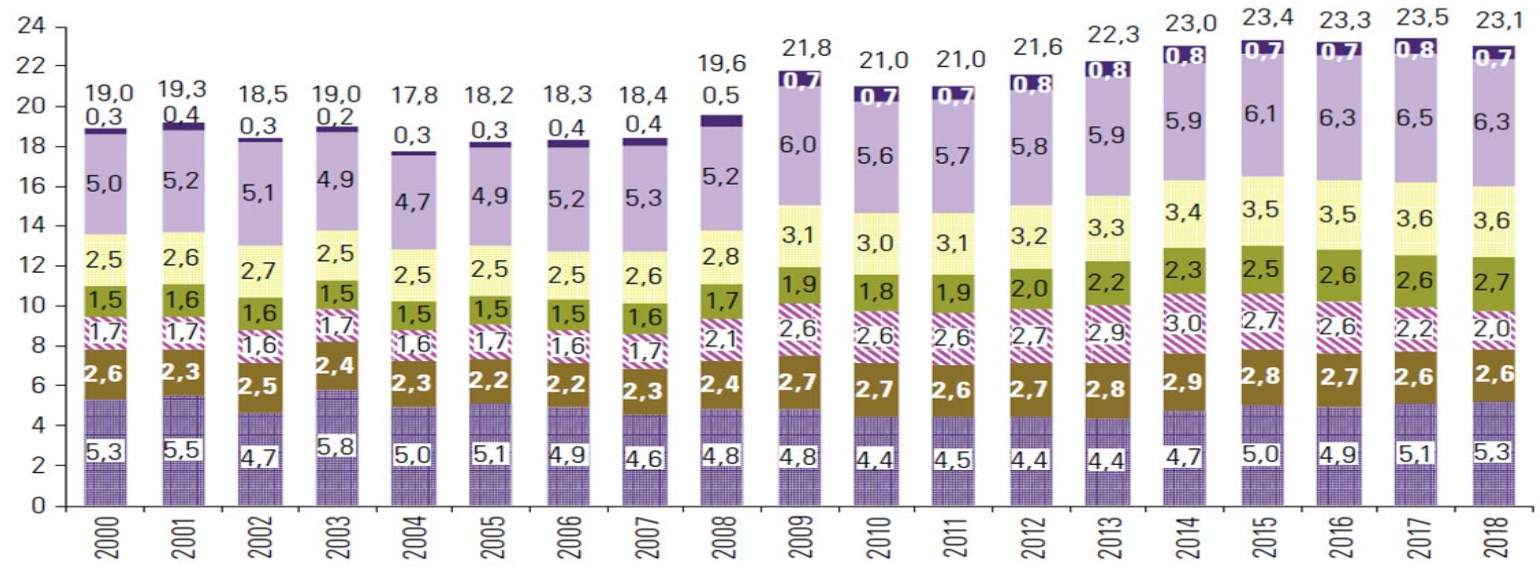

C. Centroamérica, México y República Dominicana (8 países)

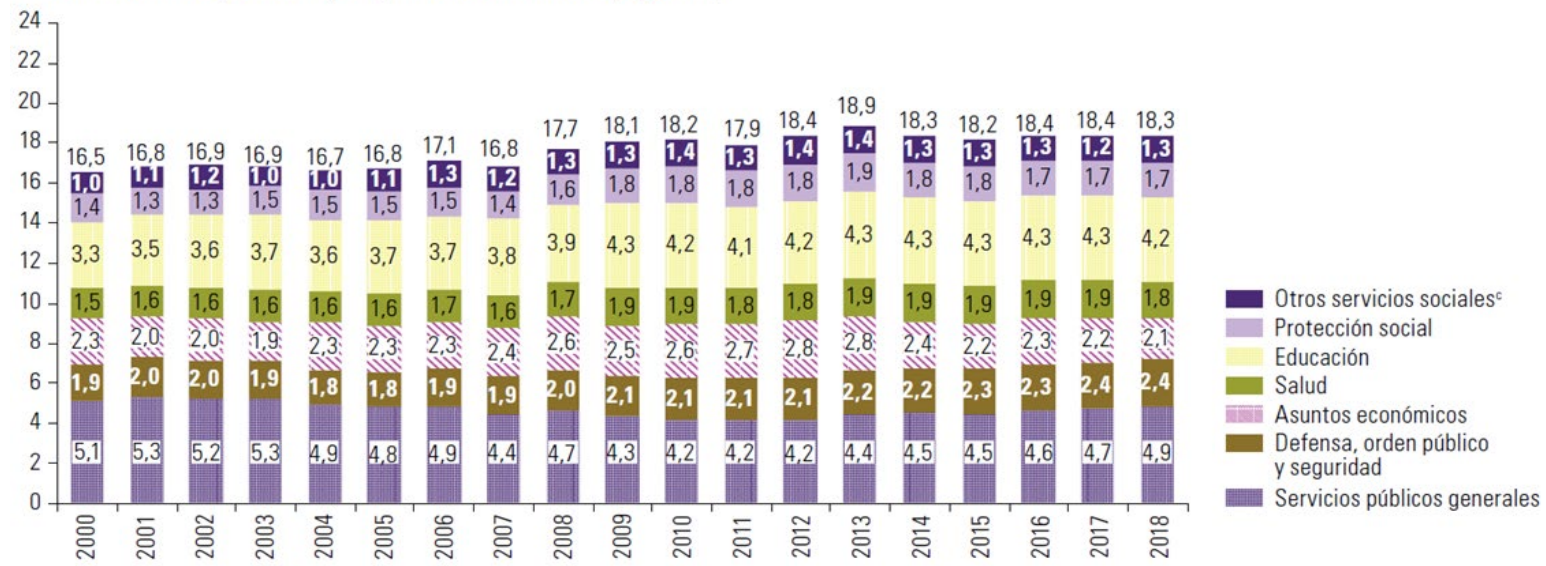




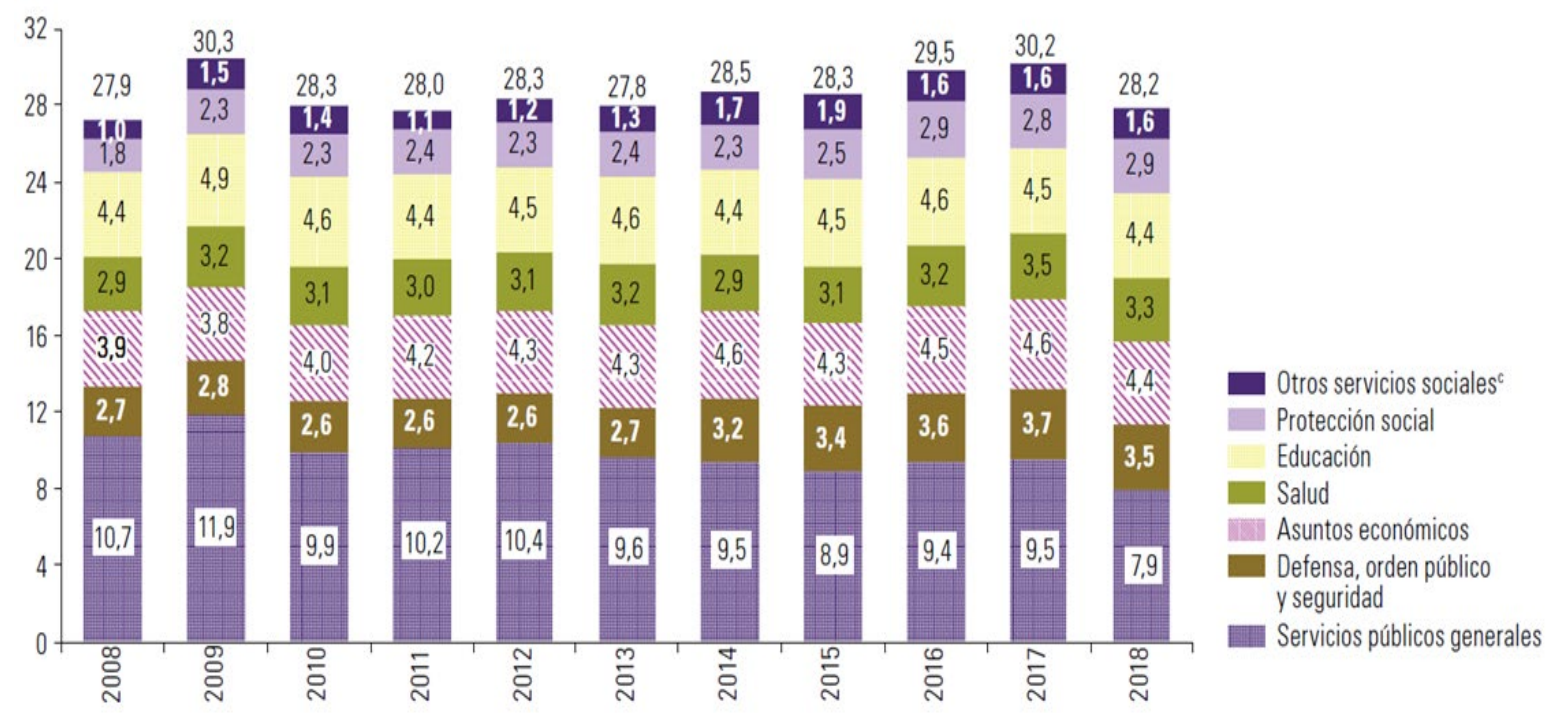

Fuente: Comisión Económica para América Latina y el Caribe (CEPAL), sobre la base de información oficial de los países.

${ }^{a}$ América Latina (gráfico A) corresponde al promedio simple de 16 países, que se dividen en dos grupos (gráficos B y C): ocho de América del Sur (Argentina, Brasil, Chile, Colombia, Ecuador, Paraguay, Perú y Uruguay) y ocho del grupo conformado por Centroamérica (Costa Rica, El Salvador, Guatemala, Honduras, Nicaragua y Panamá), México y la República Dominicana. En el caso del Caribe (gráfico D), se incluyen cinco países: Bahamas, Barbados, Guyana, Jamaica y Trinidad y Tabago.

${ }^{\mathrm{b}}$ El nivel de gasto público que se presenta aquí según la clasificación funcional no necesariamente coincide con el de la clasificación económica del gasto publicado en otros documentos de la CEPAL.

'Incluye las siguientes funciones de gobierno: protección del medio ambiente; vivienda y servicios comunitarios, y actividades recreativas, cultura y religión.

Esta evolución regional está determinada sobre todo por la dinámica del gasto en los países de América del Sur, donde, en promedio, se observó un incremento importante en todas las áreas de la política social (salud, educación, protección social y otros servicios sociales). En efecto, el gasto social aumentó casi 4 puntos del PIB en el período analizado (véase el gráfico $2 \mathrm{~B}$ ). En el caso del grupo de países conformado por Centroamérica, México y la República Dominicana, si bien se aprecia un aumento de las erogaciones en todas las áreas sociales, este es de menor magnitud; los principales cambios en las prioridades de política, por su parte, se observaron a favor de la educación y del orden público y la seguridad (véase el gráfico $2 \mathrm{C}$ ).

En ambas subregiones, el gasto en servicios públicos generales y en asuntos económicos muestra el mismo comportamiento contrapuesto que se explicó anteriormente respecto de la región de América Latina en su conjunto. Sin embargo, el punto de partida del gasto en asuntos económicos de los países sudamericanos era más bajo en relación con el PIB que el correspondiente al grupo de los países centroamericanos, México y la República Dominicana ( $1,7 \%$ y 2,3\% del PIB en 2000 , respectivamente) (véanse los gráficos $2 \mathrm{~B}$ y $2 \mathrm{C}$ ). En 2018 este ratio era muy similar entre ambos grupos: $2,0 \%$ y $2,1 \%$ del PIB, respectivamente. Así, luego del ajuste de la inversión pública y de otros gastos en servicios económicos realizado en los últimos años, los valores correspondientes a los países sudamericanos aún se encuentran por encima de los que había a comienzos de 2000, mientras que los del segundo grupo de países se ubican levemente por debajo de los niveles iniciales. 
La evolución del gasto en defensa ha sido diferente en las subregiones. En promedio, en los países de América del Sur estas erogaciones disminuyeron del 1,4\% al o,8\% del PIB en el período analizado, mientras que en los países centroamericanos, la República Dominicana y México, el promedio del gasto en defensa se mantuvo constante en valores cercanos al $0,5 \%$ del PIB (véanse los gráficos $3 \mathrm{~B}$ y ${ }_{3} \mathrm{C}$ ). En contraste, los desembolsos destinados a la función de orden público y seguridad presentan valores similares y una tendencia creciente en los dos grupos.

En la muestra de cinco países del Caribe de habla inglesa se observa un comportamiento distinto al de América Latina, ya que el gasto público aumentó durante la gran recesión de 2009, luego permaneció relativamente constante y volvió a crecer en 2016 y 2017. Como se puede apreciar en el gráfico 2D, la función del gasto que más se incrementó en 2009 fue la de servicios públicos generales, como consecuencia del aumento del pago de los intereses de la deuda en esos países. Sin embargo, el alza de los intereses se explica sobre todo por el gran aumento que hubo en Jamaica ese año, ya que luego del programa de reestructuración de la deuda de ese país en 2010, el pago de intereses se redujo considerablemente.

Además, en este grupo de países, el gasto social como proporción del PIB también experimentó un incremento durante la crisis mundial en las áreas de educación, salud, vivienda y protección social, y, en general, estos aumentos no fueron transitorios. Así el gasto social, pasó del 10,1\% del PIB en 2008 al 12\% del PIB en 2009, cifra similar a la registrada en 2018, último año con información disponible.

El aumento del gasto que se observó en los países del Caribe en 2016 y 2017 es reflejo principalmente de la ampliación de las erogaciones en asuntos económicos que fue producto del mayor dinamismo de la inversión pública. Sin embargo, en 2018, como parte de las políticas de contención del crecimiento de las erogaciones públicas, se contrajeron la inversión y el gasto en servicios económicos, aunque su nivel siguió siendo uno de los mayores de los últimos diez años ( $4,4 \%$ del PIB). En 2018 también se redujo el gasto en servicios públicos generales como resultado de las políticas de consolidación fiscal y del menor pago de intereses gracias a la tendencia a la baja de la deuda pública en este grupo de países. En particular, la contracción en esa función se explica sobre todo por la decisión de Barbados de suspender el pago de intereses y amortizaciones vencidas de la deuda pública externa para negociar un acuerdo de reestructuración con sus acreedores, que se alcanzó en 2019. Además, el gobierno de ese país suscribió, en 2018, un acuerdo cuatrienal de servicio ampliado con el Fondo Monetario Internacional que incluía una significativa consolidación fiscal ${ }^{16}$.

En el caso del gasto en defensa, orden público y seguridad, la evolución en los países caribeños es similar a la de Centroamérica, es decir, las erogaciones en materia de defensa se mantuvieron estables, en tanto que el gasto en la función de orden público y seguridad siguió una evolución creciente (véase el gráfico $3 \mathrm{D}$ ).

16 Véase CEPAL (2019c y 2019d). 
Gráfico 3

América Latina y el Caribe ( 16 países) ${ }^{\mathrm{a}}$ : evolución del gasto funcional del gobierno central por subperíodos, 2000-2018

(En porcentajes del PIB)

A. América Latina (16 países)

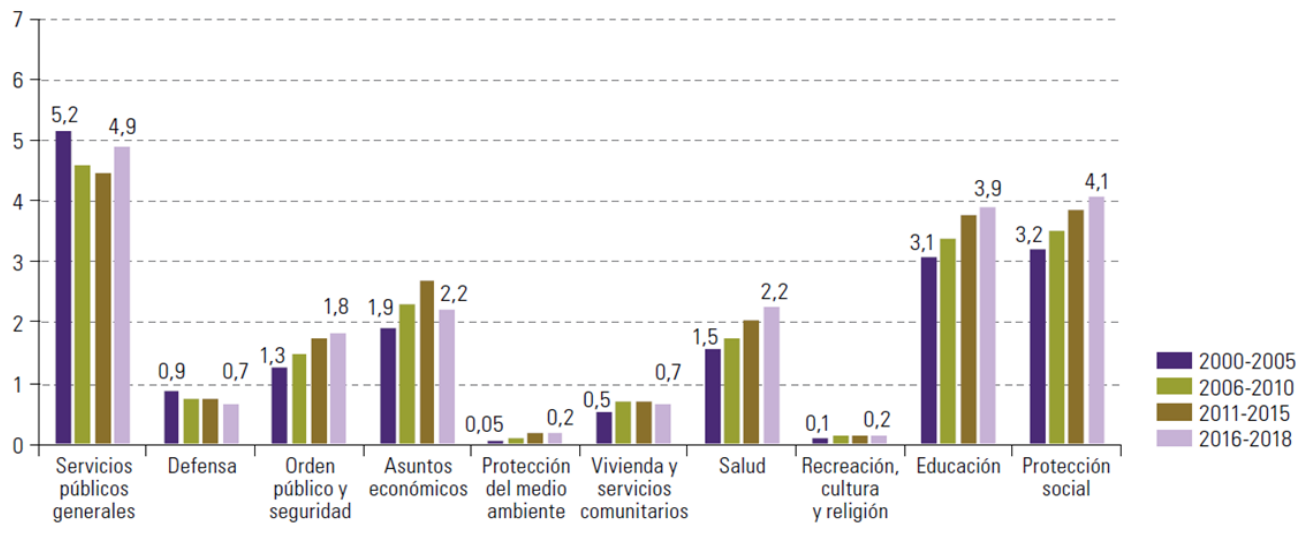

B. América del Sur (8 países)

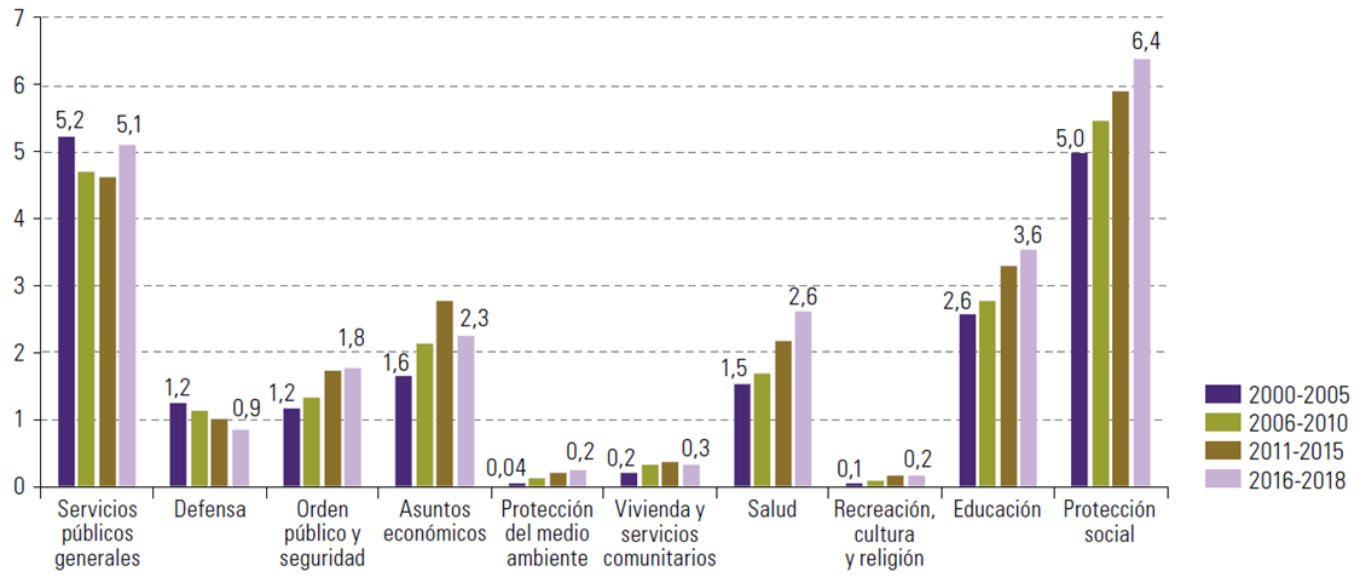

C. Centroamérica, México y República Dominicana (8 países)

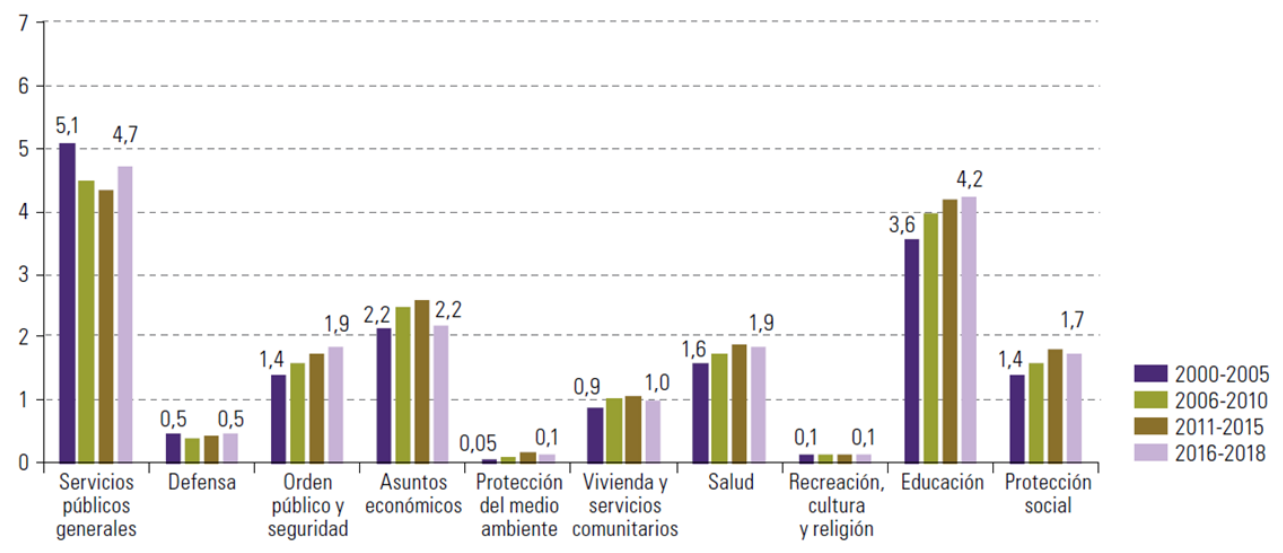


D. El Caribe (5 países)

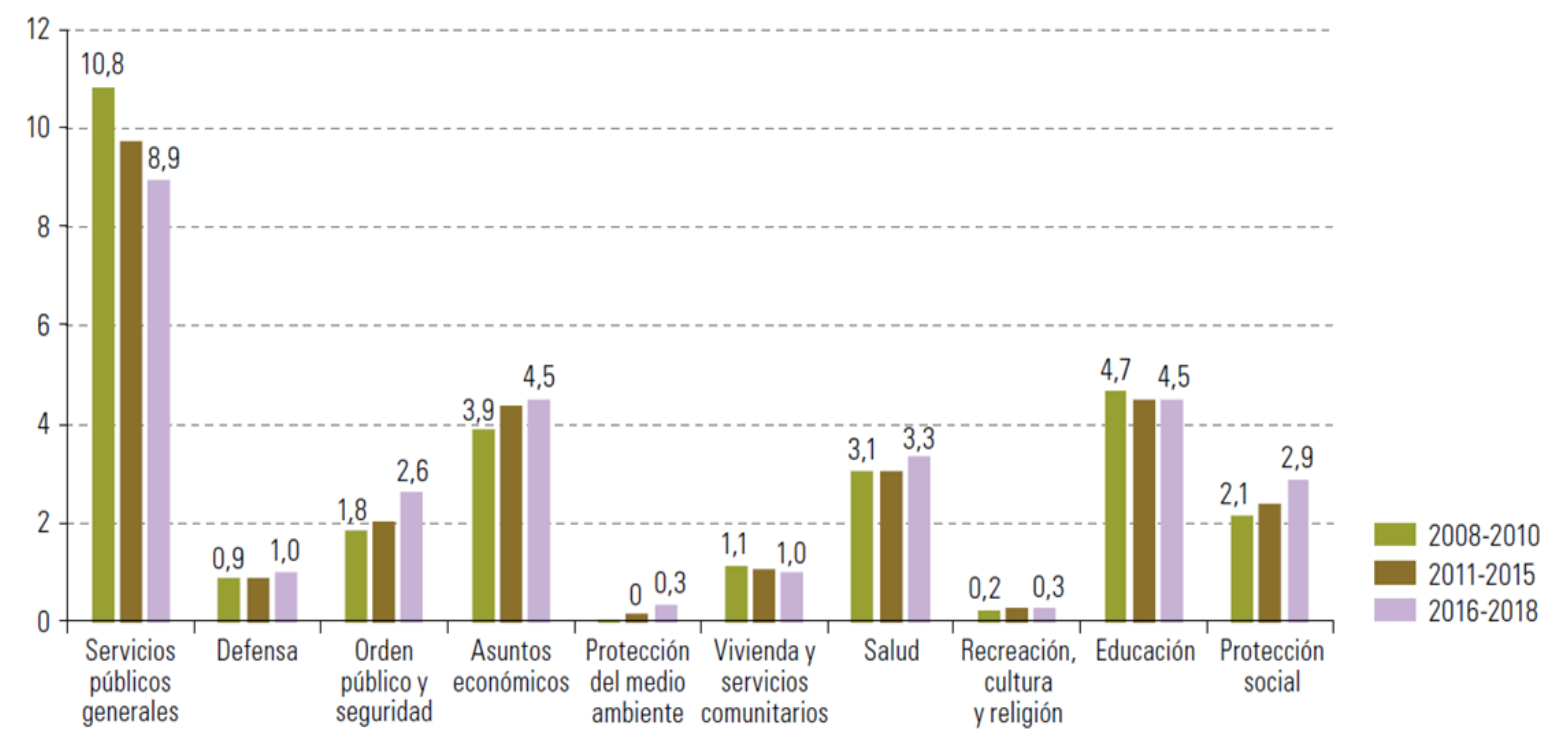

Fuente: Comisión Económica para América Latina y el Caribe (CEPAL), sobre la base de información oficial de los países.

${ }^{a}$ América Latina (gráfico A) corresponde al promedio simple de 16 países, que se dividen en dos grupos (gráficos B y C): ocho de América del Sur (Argentina, Brasil, Chile, Colombia, Ecuador, Paraguay, Perú y Uruguay) y ocho del grupo conformado por Centroamérica (Costa Rica, El Salvador, Guatemala, Honduras, Nicaragua y Panamá), México y la República Dominicana. En el caso del Caribe (gráfico D), se incluyen cinco países: Bahamas, Barbados, Guyana, Jamaica y Trinidad y Tabago.

Respecto de cómo se asignó el gasto promedio de América Latina a los distintos propósitos, la última información disponible sobre las erogaciones por funciones del gobierno revela que en 2018 más de la mitad del gasto total se dedicó a las funciones sociales, es decir, a la protección social (19\%), la educación (19\%), la salud (11\%) y otros servicios sociales (que incluye protección del medio ambiente, vivienda y servicios comunitarios, y actividades recreativas, cultura y religión). Otra función del gobierno que concentra gran parte del gasto público total es la de servicios públicos generales (24\%), dada la importancia de los egresos por concepto de intereses de la deuda pública en la mayoría de los países de la región. Le siguen en orden de importancia las erogaciones en materia de asuntos económicos (10\%) y de orden público y seguridad ( $9 \%)$, mientras que las restantes funciones tienen un peso limitado, como el gasto en defensa, que representa el $3 \%$ del total (véase el gráfico 4 ).

En la distribución de las prioridades del gasto de los gobiernos centrales entre distintos propósitos también se aprecian diferencias entre las subregiones. En los países sudamericanos, en promedio, un $58 \%$ del gasto total se destinó a funciones sociales en 2018 , en tanto que en el grupo integrado por los países de Centroamérica, México y la República Dominicana, el gasto social representó un $49 \%$ del total ese mismo año. En los países de América del Sur se destaca la alta participación de la protección social (27\%), que comprende los pagos por pensiones de vejez, sobrevivencia e invalidez, los programas de transferencias condicionadas, las prestaciones por desempleo y otros programas sociales. Además, en esa subregión, la importancia relativa de las erogaciones en servicios de salud también es superior a la correspondiente a Centroamérica, México y la República Dominicana, mientras que esta última región destina una mayor proporción de recursos a la educación ( $23 \%$ del total). 


\section{Gráfico 4}

América Latina y el Caribe (16 paises): participación relativa del gasto del gobierno central por funciones, 2018 (En porcentajes del PIB y del gasto total)

\section{A. América Latina (16 países)}

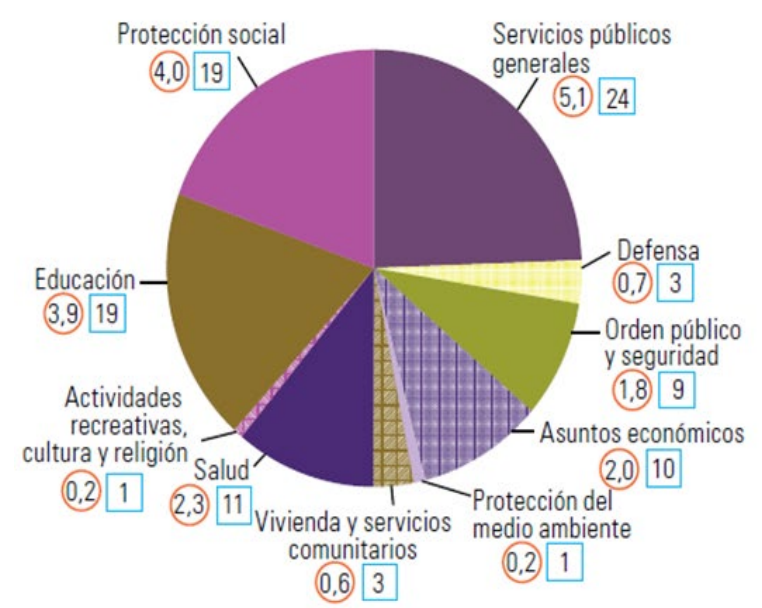

C. Centroamérica, México y República Dominicana (8 países)

\section{B. América del Sur (8 países)}

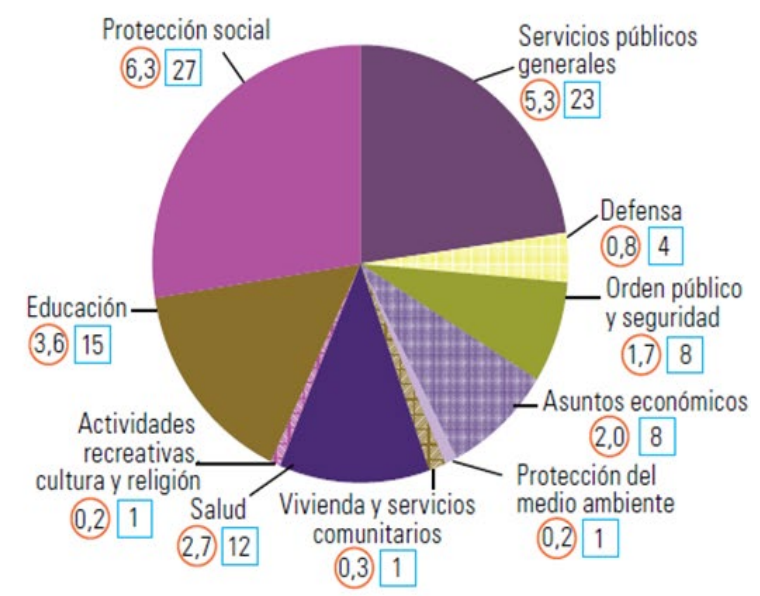

\section{El Caribe (5 países)}

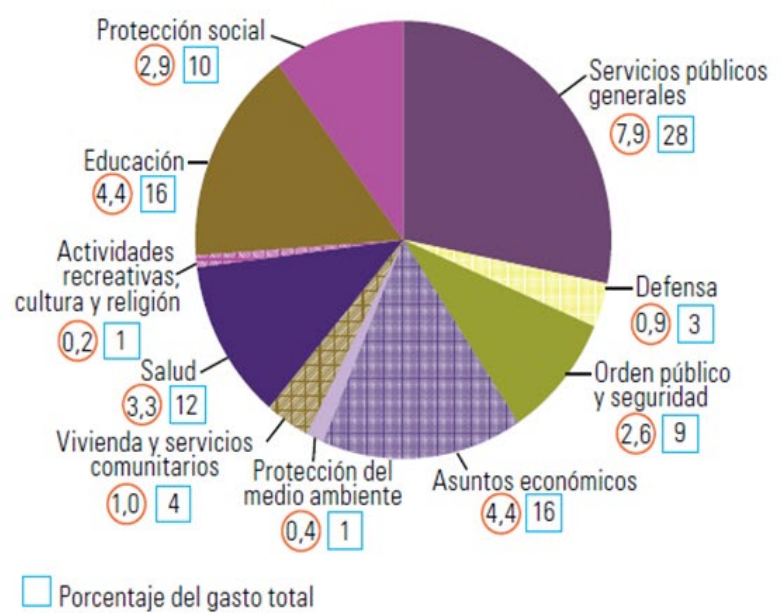

Fuente: Comisión Económica para América Latina y el Caribe (CEPAL), sobre la base de información oficial de los países.

${ }^{a}$ América Latina (gráfico A) corresponde al promedio simple de 16 países, que se dividen en dos grupos (gráficos B y C): ocho de América del Sur (Argentina, Brasil, Chile, Colombia, Ecuador, Paraguay, Perú y Uruguay) y ocho del grupo conformado por Centroamérica (Costa Rica, El Salvador, Guatemala, Honduras, Nicaragua y Panamá), México y la República Dominicana. En el caso del Caribe (gráfico D) se incluyen cinco países: Bahamas, Barbados, Guyana, Jamaica y Trinidad y Tabago. La primera cifra (superior) corresponde al porcentaje del PIB y la segunda (inferior) al porcentaje del gasto. 
Sin embargo, hay que tener en cuenta una limitación importante de estos datos, ya que, como se aclaró anteriormente, con ellos solo se mide el gasto del nivel central de gobierno y se deja fuera el nivel subnacional, que en los países federales y más descentralizados se encarga de ejecutar gran parte de las erogaciones en educación y salud. Asimismo, en algunos países los fondos de la seguridad social se consideran un subsector separado del gobierno central, por lo que las cifras de gasto en protección social tampoco son estrictamente comparables ${ }^{17}$.

Por otra parte, en el grupo conformado por los países de Centroamérica, México y la República Dominicana, la proporción de los recursos totales que se asigna a financiar el gasto en servicios públicos generales y en orden público y seguridad ( $27 \%$ y $10 \%$, respectivamente) es superior a la de sus pares sudamericanos. Asimismo, en el primer grupo de países se otorga una mayor prioridad a la vivienda y los servicios comunitarios, ya sea que el gasto en esa función se mida como proporción del PIB o como porcentaje del total de gastos.

En el caso del gasto en defensa y en asuntos económicos, las diferencias son menos significativas en cuanto a la prioridad que se asigna a estas funciones en ambas subregiones. Los países de Centroamérica, México y la República Dominicana destinan, en promedio, un 3\% del gasto total a defensa y un $11 \%$ a asuntos económicos, proporciones bastante cercanas a las que se alcanzan en los países de América del Sur, donde los valores medios son del $4 \%$ y el $8 \%$ del total, respectivamente.

En la muestra de países del Caribe de habla inglesa, las funciones más importantes en términos de gasto público son los servicios públicos generales (28\%), y los asuntos económicos y la educación ( $16 \%$ cada uno). Si bien en los últimos años se ha ido reduciendo el nivel de endeudamiento público de estos países, la proporción de recursos que se destina al pago de intereses es aún elevada, lo que repercute en la alta proporción de gastos que corresponde a los servicios públicos generales. En el caso del gasto en asuntos económicos, tal como se mencionó anteriormente, esta categoría incluye un componente importante de inversión pública, que fue más dinámica en esta subregión que en los países latinoamericanos en los últimos tres años del período analizado.

La proporción de recursos focalizados en prestaciones sociales en el Caribe de habla inglesa se ubica en el $43 \%$ del total. Así, la participación del gasto social en el total es más baja en los países caribeños que en los latinoamericanos, lo que se explica principalmente por el menor peso de los recursos destinados al gasto en protección social ( $10 \%$ del gasto total), pues en estos países los sistemas de seguridad social son administrados por entidades privadas y las prestaciones se financian a través de contribuciones sociales obligatorias. En cambio, el gasto en servicios de salud del gobierno central de los países del Caribe de habla inglesa representa una proporción similar a la del promedio de los 16 países de América Latina (12\%).

Al igual que en las otras subregiones, las demás funciones representan una proporción menor del gasto total de los gobiernos centrales del Caribe: orden público y seguridad representa el $9 \%$, vivienda y servicios comunitarios el $4 \%$, defensa el $3 \%$, protección del medio ambiente el $1 \%$, y actividades recreativas, cultura y religión también el $1 \%$.

Más allá de estas tendencias generales, hay que contemplar la heterogeneidad que existe en cuanto a la situación de los países de cada subregión, lo que se analiza en la siguiente sección.

17 Sobre este punto véase el recuadro 1, ya que en él se analiza información que tiene una cobertura institucional más amplia relativa a países en los que había estadísticas disponibles. 


\section{B. La evolución y asignación del gasto público por propósito en cada país}

En los ocho países de América del Sur analizados, el gasto público creció a un ritmo mayor que el PIB durante el período 2000-2018, aunque este incremento no fue parejo en todos ellos. Los gobiernos centrales de la Argentina, el Brasil, el Uruguay y el Ecuador fueron los que implementaron una expansión mayor de sus erogaciones. En el caso de los tres primeros, el gasto fiscal aumentó alrededor de 7 puntos del PIB entre 2000 y 2018, mientras que en el Ecuador el alza fue de 5 puntos. Es así que, en 2018, el gobierno central de estos países y de Chile fue el que más gastó en relación con el PIB: el gasto se situó entre el $22 \%$ y el $31 \%$, cifra superior a la de los demás países latinoamericanos (véase el gráfico 5 ). En los países federales como la Argentina y el Brasil, dicho gasto incluso excede el $40 \%$ del PIB cuando se considera una cobertura institucional más amplia que incluye los gobiernos intermedios y locales, como se analiza en el recuadro 1 . Algo similar sucede en Colombia, donde el gasto del gobierno general sobrepasa el $30 \%$ del PIB.

En el grupo conformado por los seis países centroamericanos, México y la República Dominicana, solo en dos el ratio del gasto público sobre el PIB fue menor en 2018 que en 2000: Guatemala y Panamá. Sin embargo, si en este último se analiza la evolución del gasto del gobierno general, que incluye la seguridad social, se aprecia una tendencia creciente del gasto público, pues al incluir este subsector se nota un alza en las erogaciones en protección social y en salud en el período estudiado.

Por otra parte, en El Salvador, México y la República Dominicana, el gasto del gobierno central creció más de 4 puntos del PIB, mientras que en Costa Rica, Honduras y Nicaragua aumentó aproximadamente 2 puntos. Los países de este grupo en que se observa el mayor gasto del gobierno central en relación con el PIB son Honduras, El Salvador y Costa Rica, con valores superiores al 20\%. No obstante, en este último país este indicador se acerca al 30\% del PIB cuando se incluye el gasto de los gobiernos subnacionales y de la seguridad social.

Por el contrario, el nivel más bajo de gasto del gobierno central como proporción del PIB en América Latina se encuentran en Guatemala (12,3\%), el Paraguay $(14,9 \%)$, la República Dominicana (17\%) y Panamá $(17,1 \%)$.

\section{Gráfico 5}

América Latina y el Caribe (21 países): gasto del gobierno central por país y subregión, 200002008 y $2018^{a}$ (En porcentajes del $P I B$ )

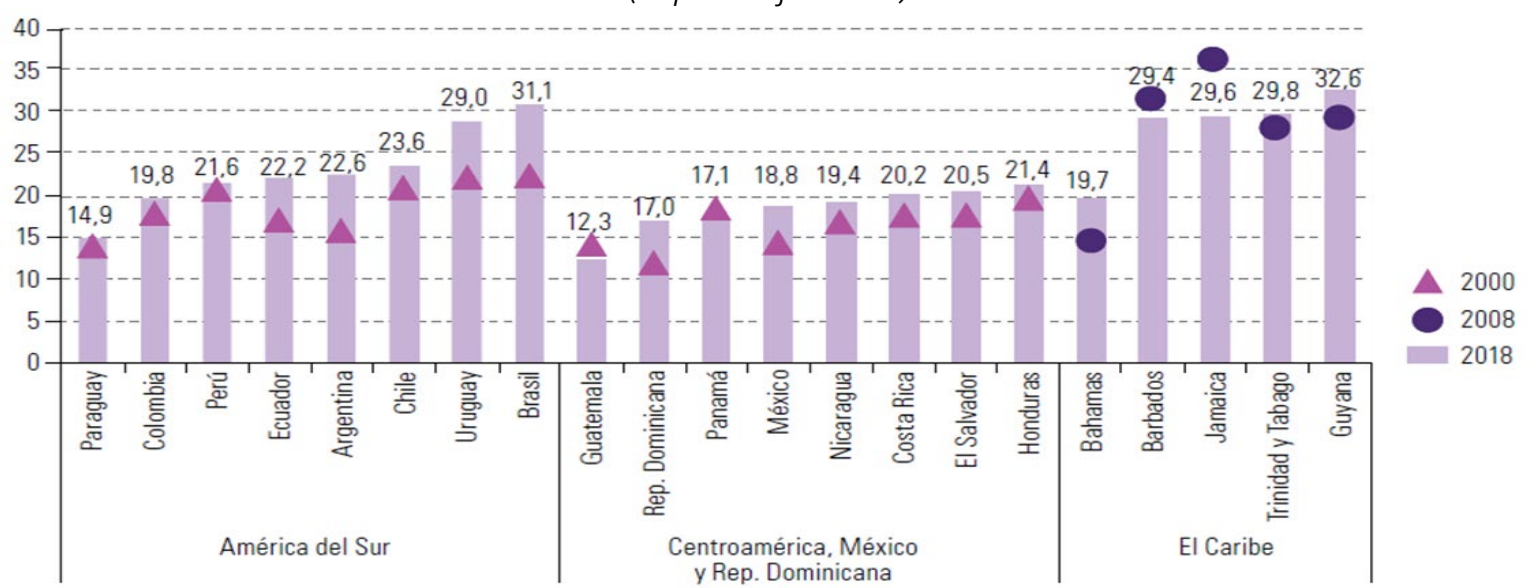

Fuente: Comisión Económica para América Latina y el Caribe (CEPAL), sobre la base de información oficial de los países. ${ }^{a}$ Los datos de Guyana y Panamá corresponden a 2017. La cobertura del Perú corresponde al gobierno general. 
En la muestra de cinco países caribeños de habla inglesa, en cuatro se alcanza un gasto del gobierno central cercano o superior al 30\% del PIB (Barbados, Jamaica, Trinidad y Tabago y Guyana), en tanto que en Bahamas el gasto fiscal es inferior al $20 \%$ del PIB. Únicamente en Barbados y Jamaica se observa que el gasto como proporción del PIB es menor en 2018 que en 2008, como consecuencia de las políticas de ajuste del gasto llevadas a cabo por las autoridades de esos países.

En cuanto al modo en que evolucionaron las prioridades relativas a la asignación de los recursos públicos, se aprecia que en los ocho países sudamericanos analizados se destinaron más fondos al financiamiento de las distintas áreas de la política social. El aumento del gasto social de los gobiernos centrales representa desde el $2 \%$ del PIB en países como Chile, el Paraguay y el Perú, hasta casi el $6 \%$ en el Ecuador durante el período examinado (véase el gráfico 6A).

Además, en algunos países, como la Argentina y el Perú, se incrementó el gasto en asuntos económicos, sobre todo en los sectores del transporte, los combustibles y la energía, en el primer país, y en el área del transporte, en el segundo. La mayor importancia de estas erogaciones en la Argentina se debió a la política de subsidios a las empresas que tenía por objeto mitigar el ajuste de los precios y las tarifas de estos servicios públicos; esto ocurrió hasta 2016, año en que se implementó una política de quita de subsidios. Es por eso que el incremento de este gasto se concentró más en transferencias corrientes que en inversión pública. En el Perú, en cambio, la mayor parte del aumento del gasto en transporte se focalizó en inversiones públicas destinadas a carreteras y transporte urbano, por ejemplo, la ampliación de la red vial peruana y la segunda línea del Metro de Lima y Callao, entre otros proyectos de inversión.

En otros países, como el Brasil y el Uruguay, se aprecia un crecimiento del gasto en servicios públicos generales, producto del incremento del pago de intereses de la deuda pública. Entre 2000 y 2018, el pago de esos intereses aumentó el 2,1\% del PIB en el Brasil y el o,8\% del PIB en el Uruguay. En contraste, en Colombia y el Perú se logró reducir la carga de los intereses de la deuda en alrededor de 1 punto del PIB, lo que permitió bajar el gasto en esa función.

La cantidad de recursos asignados a las funciones de defensa, seguridad y orden público, medida como proporción al PIB, no muestra variaciones significativas en los países de América del Sur.

\section{Gráfico 6}

América Latina y el Caribe (21 países): gasto del gobierno central por país y función, 200002008 y $2018^{a}$ (En porcentajes del PIB)

A. América del Sur (8 países)

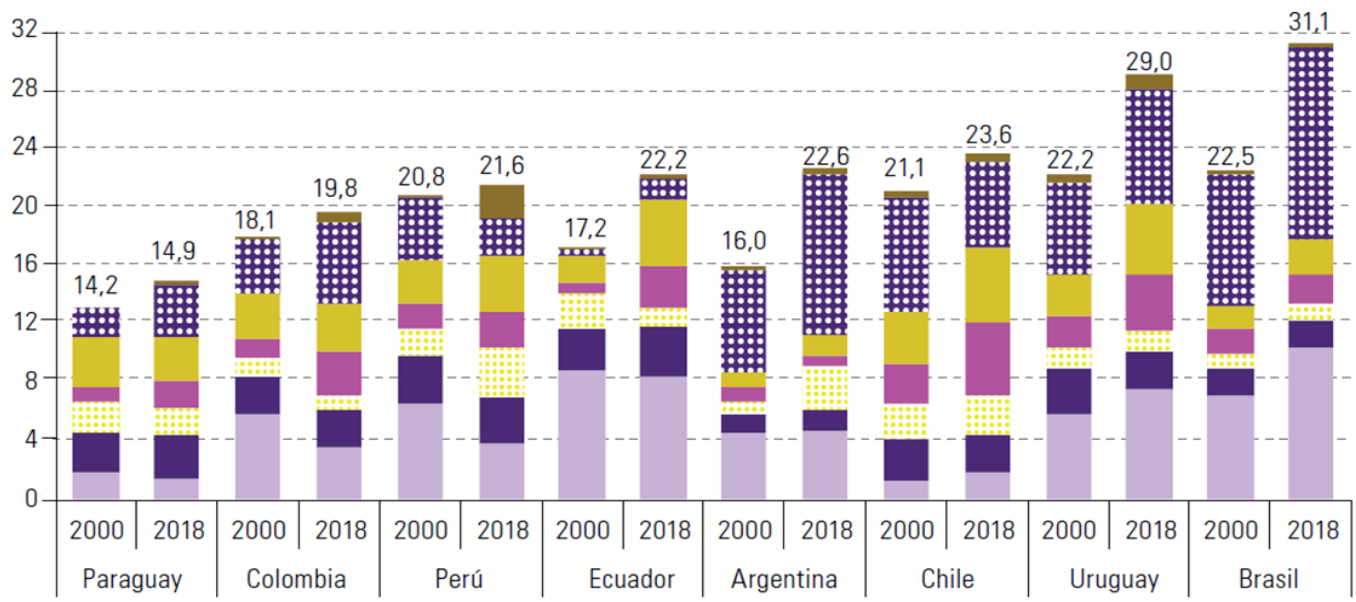


B. Centroamérica, México y República Dominicana (8 países)
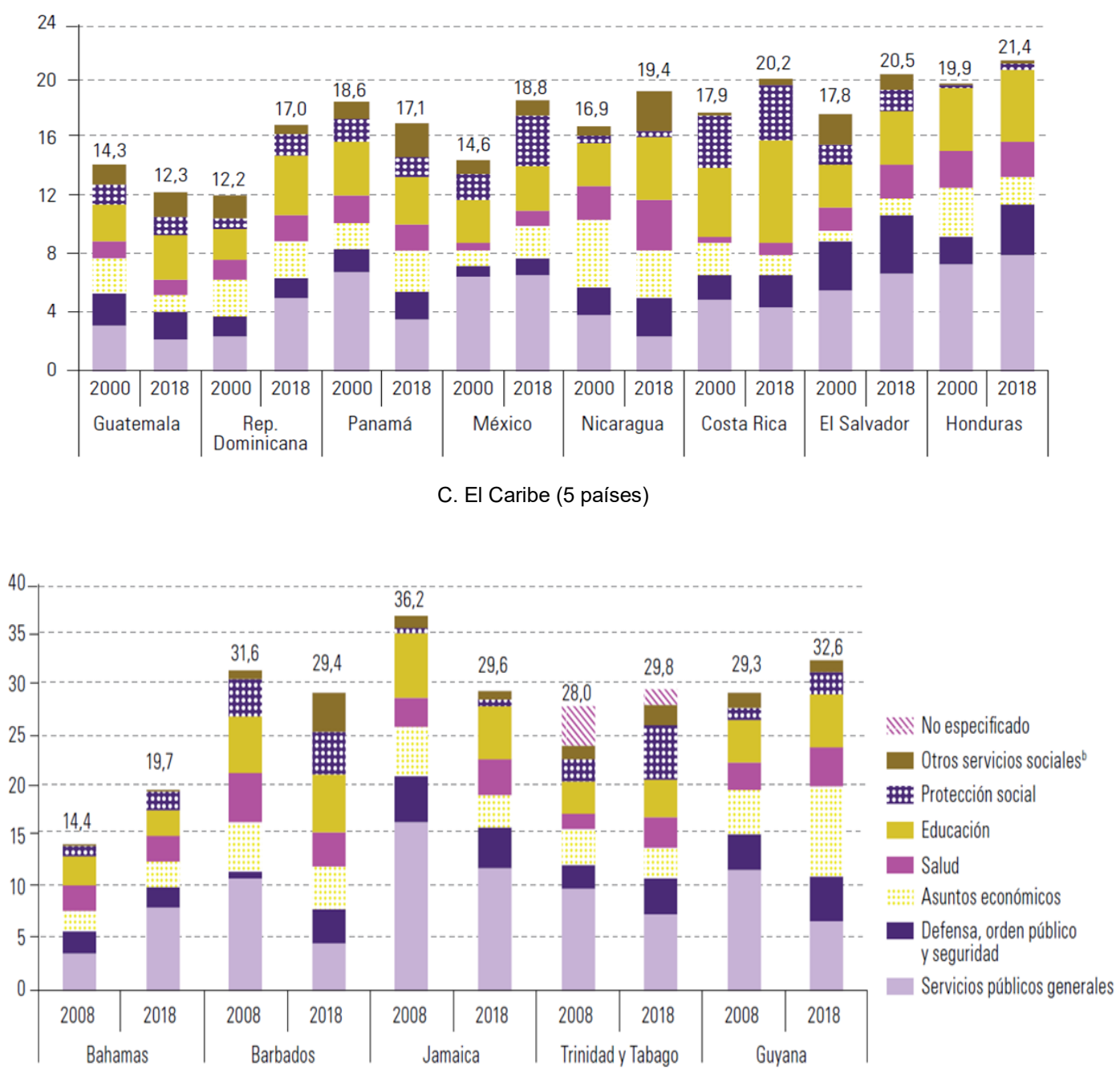

Fuente: Comisión Económica para América Latina y el Caribe (CEPAL), sobre la base de información oficial de los países.

a Los datos de Guyana y Panamá corresponden a 2017. La cobertura del Perú corresponde al gobierno general.

${ }^{\mathrm{b}}$ Incluye las siguientes funciones de gobierno: protección del medio ambiente; vivienda y servicios comunitarios, y actividades recreativas, cultura y religión.

En la muestra formada por los seis países centroamericanos, México y la República Dominicana, solo en Guatemala y Panamá el gasto de los gobiernos centrales se redujo como proporción del PIB (véase el gráfico 6B). Las erogaciones en servicios públicos generales disminuyeron en ambos países, aunque en Panamá esto ocurrió en mayor medida gracias a que el pago de los intereses de la deuda pública cayó un $2,1 \%$ del PIB entre 2000 y 2018 . Además, en Guatemala se observa una contracción del gasto en capital que se ve reflejada en menores desembolsos destinados a la función de asuntos económicos. En Panamá, en cambio, hubo un incremento de la inversión pública que se tradujo en una mayor importancia de las funciones de vivienda y asuntos económicos; en este último sector sobresale una suba del gasto público en el sector transporte. Entre las inversiones se destacan la ampliación del 
canal de Panamá, la construcción del metro en la ciudad de Panamá, los proyectos de reordenamiento vial, la construcción de la ciudad hospitalaria y el corredor de Colón ${ }^{18}$.

En los seis países de este grupo en que se observó un crecimiento del gasto total (Costa Rica, El Salvador, Honduras, México, Nicaragua y República Dominicana), se priorizó el aumento en las distintas áreas del gasto social, especialmente en el gasto destinado a educación, aunque en algunos de ellos también se destaca un incremento superior a 1 punto del PIB en las políticas de protección social (México), salud (El Salvador y Nicaragua) y vivienda (Nicaragua).

Asimismo, en México se duplicó el gasto en asuntos económicos, que pasó del 1\% del PIB en 2000 al 2,2\% del PIB en 2018. Este gasto superior en políticas vinculadas con el desarrollo económico se distribuyó entre los sectores de los combustibles y la energía, el transporte y otras industrias.

En otros países de este grupo, como en El Salvador y la República Dominicana, sobresale el alza del gasto en los intereses de la deuda pública, que fue del orden del $2 \%$ del PIB, lo que dio como resultado una erogación mayor en la función de servicios públicos generales; en algunos casos, por otra parte, se observa un mayor gasto en la función de orden público y seguridad (El Salvador, Honduras y Nicaragua).

Como se mencionó anteriormente, en dos países del Caribe de habla inglesa, Barbados y Jamaica, se contrajo el gasto del gobierno central entre 2008 y 2018 (véase el gráfico 6C). En ellos tuvo lugar una reducción significativa del gasto en servicios públicos generales, como resultado de las políticas de consolidación fiscal y de los procesos de reestructuración de la deuda pública que permitieron reducir la carga de intereses. Asimismo, en esos países se ajustó el gasto público en asuntos económicos, aunque la caída fue bastante más pronunciada en Jamaica, donde afectó sobre todo a sectores como la agricultura, la industria y el comercio. En Barbados se priorizaron los recursos destinados al orden público y la seguridad y al gasto social, en tanto que en Jamaica estas áreas sufrieron el ajuste del gasto, sobre todo en lo que respecta a los fondos dirigidos a financiar el gasto en educación.

En cuanto a los gobiernos centrales de los tres países caribeños en que el gasto subió como proporción al PIB en el período 2008-2018 (Bahamas, Guyana y Trinidad y Tabago), se aprecia un incremento del gasto social, en particular, en programas de protección social, aunque también en políticas de salud. En Bahamas, la principal causa que explica el alza del gasto público fue el aumento del pago de intereses de la deuda y de otros gastos incluidos en la función de servicios públicos generales. En Guyana y Trinidad y Tabago, en cambio, el gasto en esta función cayó considerablemente y se incrementaron los desembolsos en orden público y seguridad. Además, en Guyana aumentó de forma significativa el gasto en asuntos económicos, en especial en los sectores vinculados con la agricultura y el transporte. 


\section{Gráfico 7}

América Latina y el Caribe (21 países): distribución del gasto del gobierno central por función, 2018 (En porcentajes del gasto total)

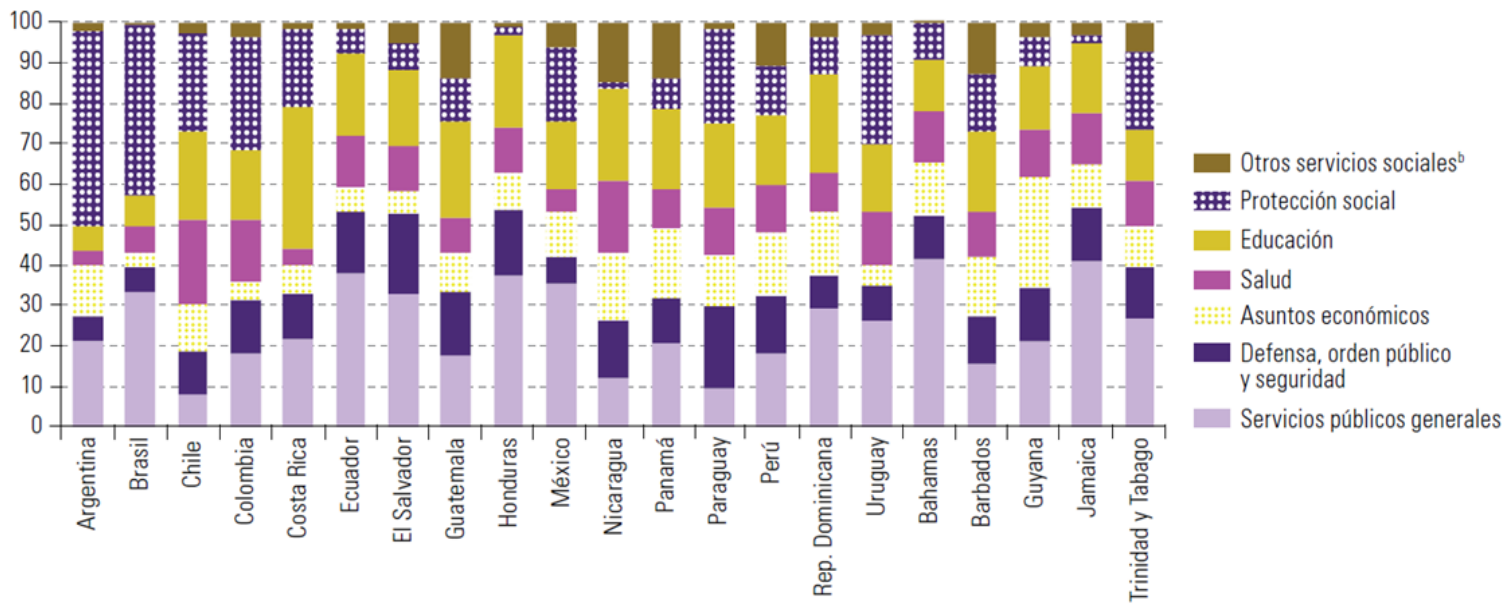

Fuente: Comisión Económica para América Latina y el Caribe (CEPAL), sobre la base de información oficial de los países.

a Los datos de Guyana y Panamá corresponden a 2017. La cobertura del Perú corresponde al gobierno general.

b Incluye las siguientes funciones de gobierno: protección del medio ambiente; vivienda y servicios comunitarios, y actividades recreativas, cultura y religión.

La prioridad que le asigna cada gobierno a los distintos propósitos del gasto varía de un país a otro. En algunos países latinoamericanos, como la Argentina, el Brasil, Chile, Colombia, Costa Rica y el Uruguay, se destina cerca del $60 \%$ o más de los recursos a financiar el gasto social (véase el gráfico 7$)^{19}$. Entre las funciones que conforman el gasto social, en estos países predomina la protección social, a excepción de Costa Rica, donde se asigna una mayor proporción del gasto a la educación. En el caso de Chile, donde gran parte del gasto en pensiones corresponde al sector privado, si bien predomina el gasto en protección social ( $24 \%$ del total), su importancia relativa es bastante similar a la de las áreas de la salud (21\%) y la educación (22\%).

Otros países latinoamericanos y caribeños donde el $20 \%$ o más del gasto total se concentra en la función educación son Guatemala, la República Dominicana, Barbados y Nicaragua. Además, en este último país la participación del gasto en salud en el total de las erogaciones es de las más elevadas de la región. Las otras funciones sociales tienen una importancia relativa menor: en Guatemala, Nicaragua, Panamá y Barbados es donde estas funciones tienen una participación mayor, con indicadores de entre el $13 \%$ y el $15 \%$ del gasto total. En estos países sobresale el gasto en la función de vivienda y servicios comunitarios, aunque en Barbados la proporción que se dirige a la protección del medio ambiente es similar a la de vivienda.

En el otro extremo, los países que asignan una menor proporción del gasto a las prestaciones sociales son el Ecuador, Honduras, Bahamas, Guyana y Jamaica, donde la participación del gasto social en el total de las erogaciones de los gobiernos centrales se sitúa entre el $35 \%$ y el $40 \%$. En estos países, la función de educación es la que adquiere una mayor prioridad entre las áreas de la política social (con una participación de entre el $13 \%$ y el $23 \%$ del gasto total).

En lo que respecta al gasto destinado a los asuntos económicos, es de destacar el caso de Guyana, donde esta función constituye el $27 \%$ del gasto total y representa casi el $9 \%$ del PIB según el último dato disponible, lo que refleja el mayor nivel de erogaciones de capital. En ese país, los principales sectores

19 Véase más información sobre el gasto social en América Latina y el Caribe en CEPAL (2019b). 
que reciben el gasto público destinado a las funciones económicas son la agricultura y el transporte. Otros países en que se destinan más recursos a los servicios económicos son Nicaragua, Panamá, el Perú, la República Dominicana y Barbados, donde se asigna entre el $15 \%$ y el $18 \%$ del presupuesto a ese propósito. Los principales sectores destinatarios son la agricultura (en el Perú), los combustibles y la energía (en la República Dominicana) y el transporte (en todos los países mencionados, a excepción de Barbados, donde esa información no se publica de forma desagregada).

En general, la erogación en las funciones de defensa, orden público y seguridad tiene mayor preponderancia en los países centroamericanos: en El Salvador, Guatemala, Honduras y Nicaragua la proporción del gasto asignada a esos propósitos se sitúa entre el $14 \%$ y el $20 \%$ del gasto total. A estos países se les suman dos países sudamericanos: el Ecuador y el Paraguay.

Por último, el gasto en servicios públicos generales se ubica por encima del $30 \%$ del gasto total de los gobiernos centrales en el Ecuador, El Salvador, Honduras, México, la República Dominicana, Bahamas y Jamaica. En la mayoría de estos casos, la alta proporción del gasto en este rubro se debe al pago de los intereses de la deuda, excepto en el caso de México, donde la importancia de las transferencias generales hacia los gobiernos subnacionales repercute en el total de esta función; en el Ecuador, por su parte, el gasto del órgano ejecutivo también es significativo.

\section{Recuadro 1 \\ El gasto público según función de gobierno en coberturas institucionales más amplias}

A lo largo de este informe se ha seguido el mismo criterio que en otras publicaciones de la CEPAL, donde se presenta, en primer lugar, un análisis completo a nivel de los gobiernos centrales, por ser esta la única cobertura institucional sobre la que se dispone de información en el conjunto de los países de la región (véase la edición 2019 del Panorama Social de América Latina). En este recuadro se complementa el análisis anterior considerando coberturas institucionales más amplias en ocho países donde hay estadísticas disponibles que permiten hacer la clasificación funcional del gasto: la Argentina, el Brasil, Colombia, Costa Rica, El Salvador, Panamá, el Paraguay y el Perúa.

El gasto público como porcentaje del PIB cambia considerablemente al comparar el valor del gobierno central con el de una cobertura más amplia que incluya los gobiernos intermedios y locales y otras entidades públicas, aunque la magnitud de esa diferencia varía de un país a otro. La diferencia depende sobre todo de la organización política e institucional de cada país y de si la cobertura del gobierno central abarca las cifras de la seguridad social o no lo hace.

La variación más relevante respecto del gasto total corresponde a la Argentina, pero las diferencias también son importantes en el Brasil, Colombia, Costa Rica, El Salvador y Panamá. En los países federales, como la Argentina y el Brasil, el gasto público total supera el $40 \%$ del PIB, en tanto que en los demás países dicho gasto se ubica en cifras cercanas al 30\% (Colombia, Costa Rica, El Salvador y Panamá) o el 20\% del PIB (Paraguay y Perú).

América Latina (8 países): gasto por función según cobertura institucional, alrededor de $201 \mathbf{8}^{\mathrm{a}}$ (En porcentajes del PIB)

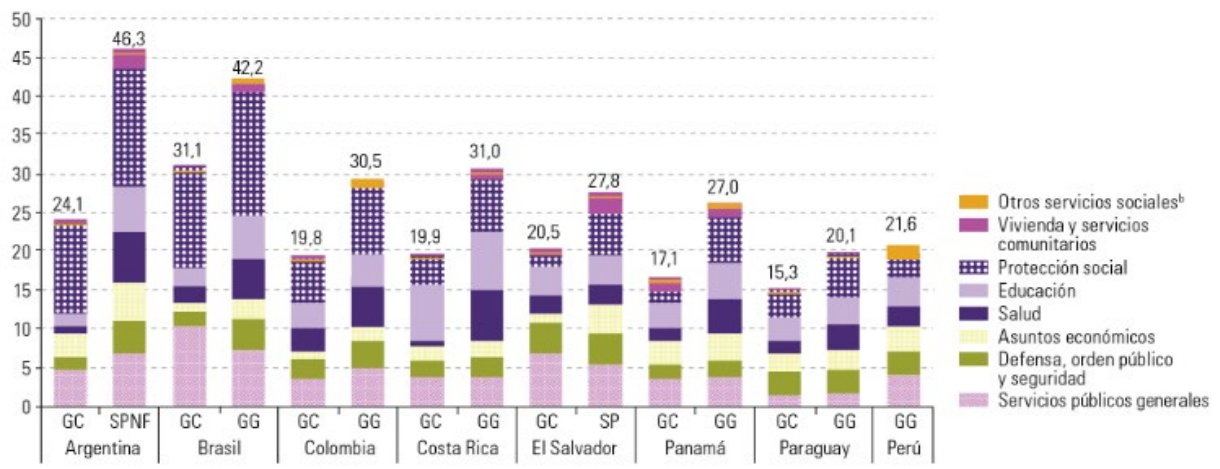

Fuente: Comisión Económica para América Latina y el Caribe (CEPAL), sobre la base de información oficial de los países. Nota: GC significa gobierno central, GG significa gobierno general, SPNF significa sector público no financiero y SP significa sector público.

a Los datos de la Argentina, Panamá y el Paraguay corresponden a 2017, y los de Costa Rica a 2016.

${ }^{\mathrm{b}}$ Incluye las siguientes funciones de gobierno: protección del medio ambiente; vivienda y servicios comunitarios, y actividades recreativas, cultura y religión. 
Al considerar coberturas institucionales más amplias, el gasto aumenta prácticamente en todas las funciones de gobierno, pero la distribución de las prioridades varía entre las distintas coberturas y entre los países.

En el caso de la función de orden público y seguridad, la cobertura más amplia revela incrementos más importantes en la Argentina y el Brasil, donde el gasto público con este propósito alcanza valores cercanos o superiores al $4 \%$ del PIB al incluir información sobre los niveles subnacionales de gobierno. Por ejemplo, en la Argentina, las provincias ejecutan más del $60 \%$ del gasto destinado a esa función.

Respecto del gasto público en asuntos económicos, el gasto del gobierno central de El Salvador apenas superaba el $1 \%$ del PIB, mientras que, cuando se considera el sector público en su conjunto (que incluye no solo a los gobiernos subnacionales, sino también a las empresas estatales), este valor se aproxima al $4 \%$ del PIB. El sector del transporte y el de combustible y la energía son los que más aumentan cuando se amplía la cobertura institucional en ese país, en parte por el gasto de la Comisión Ejecutiva Hidroeléctrica del Río Lempa. En Colombia también se observa un aumento significativo en las erogaciones vinculadas al desarrollo económico, aumento que es superior a 2 puntos del PIB cuando en la cobertura institucional se consideran los niveles subnacionales de gobierno. En efecto, el gasto en asuntos económicos llega al 3,2\% del PIB.

Sin duda, en todos los países las prioridades se inclinan hacia un mayor gasto social cuando se amplía la cobertura institucional, ya sea por la importancia de los gobiernos subnacionales en la prestación de servicios sociales o por la inclusión de la seguridad social en los países en que estos fondos se consideran un subsector separado del gobierno central. En la mayoría de los países analizados, la proporción de recursos destinados al gasto público social se acerca al $65 \%$ del gasto total o lo supera. Esto ocurre en la Argentina, el Brasil, Colombia, Costa Rica, Panamá y el Paraguay, en tanto que en El Salvador y el Perú la participación del gasto social en el total llega al 52\%. En términos del PIB, la mayor participación del gasto social se alcanza en la Argentina y el Brasil (30,4\% y $27,5 \%$, respectivamente); en un nivel intermedio que ronda el $20 \%$ del PIB se ubican Colombia, Costa Rica y Panamá (19,9\%, 22,5\% y 17,5\%, respectivamente), y en un nivel inferior al $15 \%$ se sitúan El Salvador, el Paraguay y el Perú $(14,6 \%, 12,8 \%$ y $11,2 \%$, respectivamente).

En cuanto a la importancia de las funciones que forman parte de la definición de gasto social que emplea la CEPAL, se aprecian algunas diferencias entre estos países. En lo que respecta al gasto en salud, al comparar la cobertura del gobierno central con una cobertura más amplia, el mayor incremento surge en la Argentina, por la importancia de las prestaciones en salud de las provincias y las obras sociales, y en Costa Rica, porque se incluye la seguridad social en la cobertura del gobierno general. También se distinguen aumentos relevantes en el Brasil, Colombia y Panamá.

En el caso del gasto en educación, la relevancia de los gobiernos subnacionales se nota en la Argentina y el Brasil, donde este gasto está más descentralizado. Así, al pasar de la cobertura que solo abarca el gobierno central a otra más amplia, el gasto en educación aumenta del 1,6\% al 5,8\% del PIB en el primer país, y del 2,4\% al $5,4 \%$ del PIB en el segundo.

El gasto en protección social se amplía considerablemente en todos los países cuando se incluyen las erogaciones de otras unidades y organismos de gobierno, con incrementos que van desde el $2 \%$ al $4,5 \%$ del PIB según el país. Las subas más significativas se aprecian en Panamá y El Salvador, pues en la cobertura más amplia se incluyen las pensiones y otras prestaciones de la seguridad social. Así, en estos países, el gasto en protección social aumenta del $1,3 \%$ al $5,9 \%$ del PIB y del $1,4 \%$ al $5,4 \%$ del PIB, respectivamente. Las subas en Colombia, Costa Rica y el Paraguay, si bien son algo menores, también se explican sobre todo por la consideración de la seguridad social en la cobertura del gobierno general.

Por último, en el caso de la función de la vivienda y los servicios comunitarios, el alza más relevante tiene lugar en la Argentina, Costa Rica y El Salvador, en tanto que en otros servicios sociales (entre los que se encuentra el gasto en protección del medio ambiente y en actividades recreativas, cultura y religión), los cambios son más pequeños.

En definitiva, este análisis demuestra la importancia de que en los países de la región donde no hay estadísticas de gasto funcional a nivel del gobierno general o, en su defecto, de otras coberturas más amplias, se haga un esfuerzo por avanzar en publicarlas de forma periódica y oportuna.

Fuente: Comisión Económica para América Latina y el Caribe (CEPAL), sobre la base de información oficial de los países.

a En el caso del Perú, la serie es la misma que en las otras secciones del documento, pues solo se dispone de datos relativos a la cobertura de gobierno general. Sin embargo, en el país no se incluye el gasto del Seguro Social de Salud (EsSalud) en la definición de gobierno general, aunque sí se considera el gasto de la seguridad social en prestaciones previsionales. 


\section{Recuadro 2 \\ El gasto en salud en los países de América Latina y el Caribe}

La pandemia del COVID-19 encuentra a los países de la región en una situación dispar con respecto a los recursos fiscales que se destinan a políticas y servicios de salud. Varios países aún están muy alejados de la meta propuesta en la Agenda de salud sostenible para las Américas 2018-2030 que establece lograr un gasto público destinado a la salud de por lo menos el 6\% del PIB en el año 2030. Esto con el fin de alcanzar un financiamiento adecuado y sostenible de la salud y así avanzar hacia el acceso y cobertura universal de la salud ${ }^{20}$.

En las últimas dos décadas los gobiernos de América Latina y el Caribe han ido aumentando los recursos fiscales destinados al financiamiento de la salud (véase el siguiente gráfico). Si bien la tendencia creciente en el gasto en salud de los gobiernos centrales se observa en todas las subregiones, el aumento es más acentuado en los países de América del Sur que en el grupo formado por los seis países de Centroamérica, México y la República Dominicana. Ambas subregiones parten en el año 2000 con un gasto promedio del 1,5\% del PIB para el gobierno central, pero el primer grupo de países alcanza en 2018 un nivel de 2,6\% del PIB y el segundo grupo de 1,8\% del PIB.

En la muestra de cinco países del Caribe de habla inglesa con información disponible, el promedio del gasto en salud del gobierno central subió de $2,9 \%$ a 3,3\% del PIB entre el año 2008 y el 2018 , valores que se han mantenido por encima de los del promedio de América Latina. Sin embargo, estos datos solo incluyen el gasto del gobierno central, es decir, no tienen en cuenta a los gobiernos subnacionales ni a la seguridad social en los países que consideran a estos fondos como un subsector separado del nivel central de gobierno. Cuando esta información se tiene en cuenta, el gasto promedio de los países latinoamericanos supera al de los caribeños como se mostrará más adelante.

El comportamiento al alza de los recursos destinados a financiar el gasto público en salud es bastante generalizado en la región, pues solo tres países no experimentaron aumentos durante el periodo analizado (Barbados, Guatemala y Honduras).

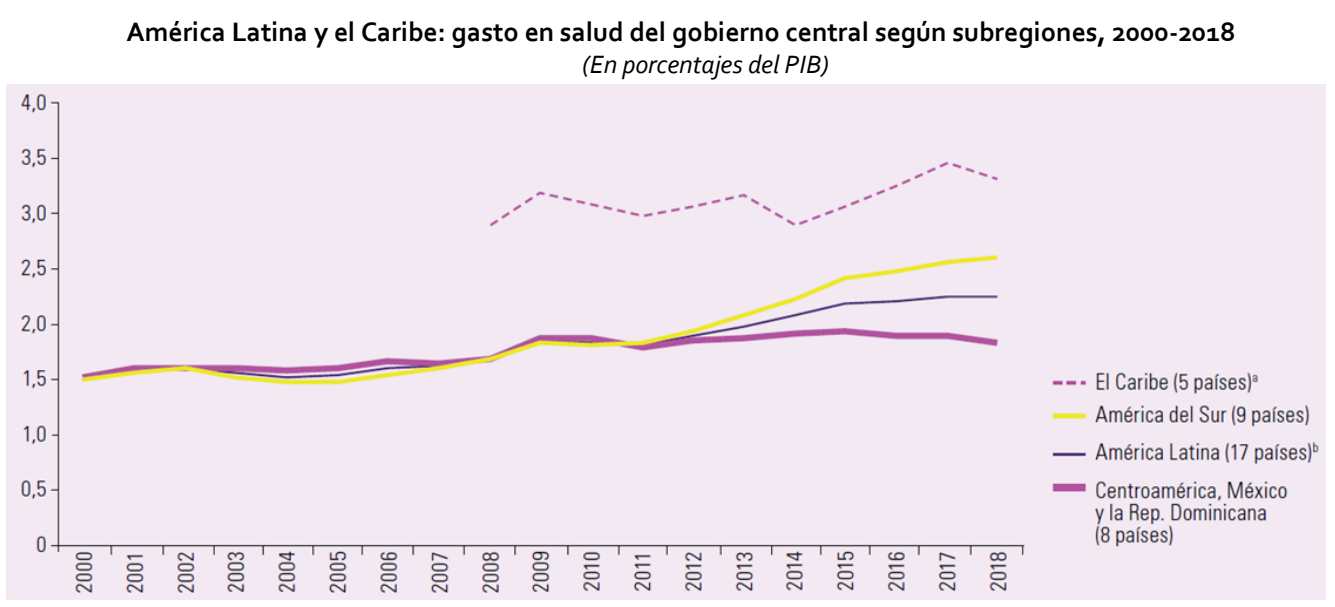

Fuente: Comisión Económica para América Latina y el Caribe (CEPAL), sobre la base de información oficial de los países.

${ }^{a}$ Corresponde al promedio simple de los valores de 5 países del Caribe: Bahamas, Barbados, Guyana, Jamaica y Trinidad y Tabago.

${ }^{b}$ Corresponde al promedio simple de los valores de 17 países de América Latina con información disponible: Argentina, Brasil, Bolivia, Chile, Colombia, Costa Rica, Ecuador, El Salvador, Guatemala, Honduras, México, Nicaragua, Panamá, Paraguay, Perú, República Dominicana y Uruguay. La cobertura del Perú corresponde a gobierno general.

Por otra parte, resulta interesante conocer cuál es la situación de los países respecto del financiamiento del gasto total en salud, es decir, en relación con la composición entre los recursos aportados por el sector público y el privado para cubrir los servicios sanitarios (véase el siguiente cuadro). De acuerdo con los últimos datos de la Organización Mundial de la Salud, la distribución entre el gasto público y privado para el promedio de países de América Latina es muy similar a la del promedio de países del Caribe, donde el $58 \%$ está a cargo del sector público (que incluye el gasto del gobierno y los seguros contributivos obligatorios, que principalmente corresponden a la Seguridad Social)b, mientras que el $42 \%$ restante es gasto privado, ya sea financiado a través de seguros privados voluntarios o gasto de bolsillo de los hogares.

20 Véase el objetivo 4 (meta 4.1) de la Agenda de salud sostenible para las América 2018-2030 (OPS/OMS, 2017). Disponible en https://www.paho.org/hq/index.php?option=com_content\&view=article\&id=13246:health-agendaamericas\&ltemid=42349\&lang=es 


\section{Cuadro 1}

América Latina y el Caribe (33 países): gasto público y privado en salud por país, 2017 (En porcentajes del PIB y del total de gasto en salud)

\begin{tabular}{|c|c|c|c|c|}
\hline \multirow{2}{*}{ Pais } & \multicolumn{3}{|c|}{ Gasto en salud en porcentajes del PIB } & \multirow{2}{*}{$\begin{array}{l}\text { Gasto de bolsillo en porcentajes } \\
\text { del gasto total en salud }\end{array}$} \\
\hline & Total & Público ${ }^{a}$ & Privado $^{b}$ & \\
\hline América Latina y el Caribe ${ }^{e}$ & 6,7 & 3,8 & 2,7 & 33,3 \\
\hline América Latina ${ }^{e}$ & 7,5 & 4,3 & 3,0 & 32,1 \\
\hline Argentina & 9,1 & 6,7 & 2,5 & 15,0 \\
\hline Bolivia (Estado Plurinacional de) & 6,4 & 4,5 & 1,6 & 25,1 \\
\hline Brasil & 9,5 & 4,0 & 5,5 & 27,5 \\
\hline Chile & 9,0 & 5,4 & 3,6 & 33,5 \\
\hline Colombia & 7,2 & 5.3 & 1,9 & 16,3 \\
\hline Costa Rica & 7,3 & 5,5 & 1,6 & 21,3 \\
\hline Cuba & 11,7 & 10,5 & 1,2 & 10,5 \\
\hline República Dominicana & 6,1 & 2,8 & 3,3 & 44,7 \\
\hline Ecuador & 8,3 & 4,4 & 3,8 & 39,4 \\
\hline El Salvador & 7,2 & 4,6 & 2,6 & 28,7 \\
\hline Guatemala & 5,8 & 2,0 & 3,8 & 54,1 \\
\hline Haiti & 8,0 & 1,1 & 7,0 & 40,2 \\
\hline Honduras & 7,9 & 3,5 & 4,4 & 48,7 \\
\hline México & 5,5 & 2,8 & 2,3 & 41,3 \\
\hline Nicaragua & 8,6 & 5,5 & 2,8 & 32,6 \\
\hline Panamá & 7,3 & 4,4 & 2,4 & 33,3 \\
\hline Paraguay & 6,7 & 3,0 & 3,6 & 44,2 \\
\hline Perú & 5,0 & 3,2 & 1.4 & 28,2 \\
\hline Uruguay & 9,3 & 6,2 & 3,1 & 17,5 \\
\hline $\begin{array}{l}\text { Venezuela (República } \\
\text { Bolivariana de) }\end{array}$ & 3,2 & 0,8 & 2,4 & 40,0 \\
\hline El Caribe ${ }^{e}$ & 5,5 & 3,1 & 2,2 & 35,3 \\
\hline Antigua y Barbuda & 4,5 & 2,1 & 2,4 & 35,0 \\
\hline Bahamas & 5,8 & 2,5 & 3,2 & 31,0 \\
\hline Barbados & 6,8 & 3,1 & 3,7 & 46,3 \\
\hline Belice & 5,6 & 3,9 & 1.4 & 24,2 \\
\hline Dominica & 5,8 & 3,8 & 1,8 & 31,0 \\
\hline Granada & 4,8 & 2,1 & 2,5 & 52,4 \\
\hline Guyana & 4,9 & 3,1 & 1,6 & 32,5 \\
\hline Jamaica & 6,0 & 4,0 & 2,0 & 17,2 \\
\hline Saint Kitts y Nevis & 5,0 & 2,3 & 2,4 & 47,8 \\
\hline Santa Lucía & 4,5 & 2,2 & 2,0 & 44,8 \\
\hline San Vicente y las Granadinas & 4,5 & 2,8 & 1,4 & 31,2 \\
\hline Suriname & 6,2 & 4,1 & 1,6 & 26,4 \\
\hline Trinidad y Tabago & 7,0 & 3,7 & 2,8 & 39,8 \\
\hline
\end{tabular}

Fuente: Organización Mundial de la Salud (OMS).

Se siguen las siguientes definiciones de la Organización Panamericana de la Salud (OPS):

a Gasto público: Gasto en salud financiado a través de fuentes obligatorias de recursos como son los impuestos, las cotizaciones a la seguridad social y los aportes obligatorios a esquemas de aseguramiento en salud, tanto de empleados como de empleadores e incluyendo el aporte fiscal a estos.

${ }^{b}$ Gasto privado: Gasto en salud financiado por fuentes voluntarias de financiamiento como el pago de primas de seguros privados (prepago) y el gasto de bolsillo en bienes y servicios de salud en el momento de la atención (pago directo).

cPromedios simples.

${ }^{\mathrm{d}}$ Los datos de Venezuela corresponden a 2016.

Esta distribución promedio oculta realidades muy diferentes entre los países. Por un lado, hay casos donde más del $70 \%$ del gasto en salud es financiado por el gobierno, la seguridad social $u$ otros esquemas contributivos obligatorios, como en Argentina, Bolivia, Colombia, Costa Rica, Cuba y Surinam. En contraste, en otros la proporción del gasto privado en salud supera el 55\% como en Bahamas, Brasil, Guatemala, Haití, Honduras y Venezuela.

La OPS (2019) sostiene que un atributo primordial para alcanzar la equidad universal es la capacidad del sistema de salud de garantizar el acceso, independientemente de la solvencia de las personas y para dar seguimiento a esta capacidad utiliza como indicador básico el gasto de bolsillo en salud como porcentaje del gasto total en salud. En ese sentido, varios países presentan un elevado gasto de bolsillo que es cercano o superior al $40 \%$ del gasto total en salud, como Ecuador, Guatemala, Haití, Honduras, México, Paraguay, República Dominicana y Venezuela en América Latina, y Barbados, Granada, Saint Kitts y Nevis, Santa Lucía y Trinidad y Tobago en el Caribe. 
Por otra parte, es de destacar que se aprecian diferencias en los niveles de gasto total en salud tanto entre regiones como entre países. En el promedio de veinte países de América Latina el gasto total en salud es de 7,5\% del PIB, donde los mayores niveles tienen lugar en Argentina, Brasil, Chile, Cuba y Uruguay con valores que superan el $9 \%$ del PIB. El gasto total en salud en el promedio de trece países del Caribe es bastante menor, ya que se sitúa en $5,5 \%$ del PIB donde Barbados y Trinidad y Tobago registran los mayores gastos (alrededor de $7 \%$ del PIB).

Por último, respecto de la magnitud del gasto público en salud, solo tres de los 33 países de América Latina y el Caribe han alcanzado la meta de destinar por lo menos el $6 \%$ del PIB al gasto público en salud para avanzar hacia un sistema universal: Argentina, Cuba y Uruguay; mientras que cuatro países se van acercando con un nivel del orden del $5,5 \%$ del PIB: Chile, Colombia, Costa Rica y Nicaragua. En el otro extremo, muy rezagados, con un valor de gasto público en salud igual o inferior al 3\% del PIB se hallan Antigua y Barbuda, Bahamas, Granada, Guatemala, Haití, México, Paraguay, República Dominicana, Saint Kitts y Nevis, Santa Lucía, San Vicente y las Granadinas, y Venezuela.

En conclusión, si bien los países de la región han realizado un esfuerzo por incrementar los recursos públicos destinados al financiamiento de los servicios de salud durante las últimas décadas, estos todavía son insuficientes en la mayoría de los países para asegurar el acceso universal de la población a los servicios de salud y más aún para dar respuesta ante esta situación de pandemia. Los bajos niveles de gasto público en salud y la elevada proporción del gasto de bolsillo de los hogares en varios países, pone en evidencia los mayores desafíos que enfrentan estos gobiernos respecto de la disponibilidad de recursos con los que cuentan para hacer frente al COVID-19.

Fuente: Elaboración propia sobre la base de la CEPAL y la OMS.

a Véase el objetivo 4 (meta 4.1) de la Agenda de salud sostenible para las América 2018-2030 (OPS/OMS, 2017). Disponible en https://www.paho.org/hq/index.php?option=com_content\&view=article\&id=13246:health-agenda-americas\&ltemid=42349\&lang=es.

b Para el concepto de gasto público y privado en salud se sigue la definición de la OPS (2019). Esto es, se considera gasto público en salud aquel financiado a través de fuentes obligatorias de recursos como son los impuestos, las cotizaciones a la seguridad social y los aportes obligatorios a esquemas de aseguramiento en salud, tanto de empleados como de empleadores e incluyendo el aporte fiscal a estos. El gasto privado en salud es aquel financiado por fuentes voluntarias como el pago de primas de seguros privados (prepago) y el gasto de bolsillo en bienes y servicios de salud en el momento de la atención (pago directo).

\section{Análisis del vínculo entre la inversión pública y el gasto público funcional}

Tal como se remarcó en el apartado A de la sección I, y como lo demuestran los datos empíricos sobre los multiplicadores fiscales que allí se presentan, la inversión pública desempeña un rol clave en el crecimiento económico y en el logro de los Objetivos de la Agenda 2030. Es por ello que en esta sección se analiza de manera detallada cuáles han sido las prioridades del gasto de capital y su evolución, es decir, en qué funciones y sectores han invertido los gobiernos de la región y en cuáles han reducido el gasto de capital durante los últimos años ${ }^{21}$.

En los 16 países de América Latina respecto de los cuales se dispone de información correspondiente al período 2000-2018, la evolución del gasto de capital de los gobiernos centrales se correlaciona en gran medida con el gasto en asuntos económicos, debido a que gran parte de la inversión pública se destina a esa función de gobierno (véase el gráfico 8 ). A partir de 2007, la inversión pública comenzó a recuperarse en la región y tuvo un crecimiento aún más vigoroso en 2008-2009, puesto que los gobiernos aprovecharon el espacio fiscal y utilizaron el gasto de capital como instrumento de política contracíclica frente a la crisis financiera mundial, con lo que apoyaron la recuperación de la actividad económica. Esta tendencia continuó hasta que el gasto de capital alcanzó un valor máximo en 2013. Así, el promedio simple del gasto público de capital de los 16 países de América Latina aumentó 1,1 punto porcentual del PIB y pasó del 2,9\% al $4 \%$ del PIB entre 2000 y 2013 , en tanto que el gasto en asuntos económicos creció de un promedio del $2 \%$ del PIB al $2,8 \%$ en ese mismo lapso. A partir de 2014, en un contexto de desaceleración económica, caída del precio de los productos básicos, merma de la recaudación y deterioro de las cuentas fiscales, el gasto público de capital fue disminuyendo gradualmente hasta ubicarse en un promedio del 3,1\% del PIB en 2018-2019 en la

21 En esta sección se utilizan los gastos de capital como indicador indirecto para medir la inversión pública. Dichos gastos incluyen la adquisición de activos de capital fijo, las transferencias de capital y otros gastos de capital. 
muestra de países latinoamericanos. El recorte de los gastos de capital también se vio reflejado en una menor asignación de recursos para financiar el gasto en asuntos económicos, que cayó hasta situarse en $2 \%$ del PIB en 2018 en el promedio de los países de América Latina.

La contracción del gasto de capital entre 2013 y 2019 fue bastante generalizada en la región, aunque hay algunas excepciones. Si se compara 2019 con 2013, el gasto de capital se recortó en 12 de 16 países de América Latina: Argentina, Brasil, Chile, Colombia, Ecuador, El Salvador, Guatemala, Honduras, México, Panamá, Perú y República Dominicana. En el Uruguay, por su parte, los valores de 2019 son similares a los de 2013, y solo hay tres países donde el gasto de capital era más alto en 2019 que seis años atrás: Costa Rica, Nicaragua y Paraguay.

\section{Gráfico 8}

América Latina y el Caribe (16 países): gasto de capital y en asuntos económicos del gobierno central, 2000-2019 (En porcentajes del PIB)

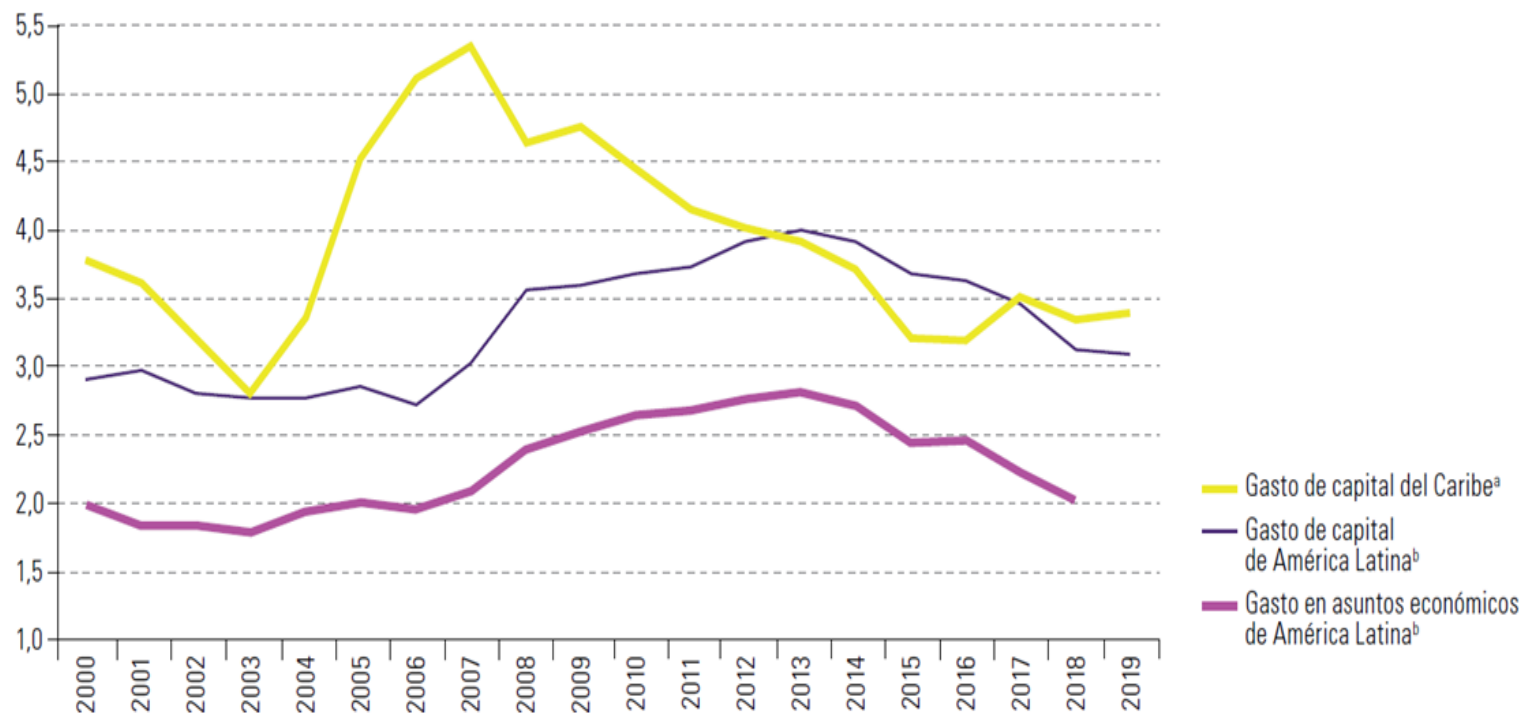

Fuente: Comisión Económica para América Latina y el Caribe (CEPAL), sobre la base de información oficial de los países.

${ }^{a}$ Corresponde al promedio simple de los valores de 16 países de América Latina: Argentina, Brasil, Chile, Colombia, Costa Rica, Ecuador, El Salvador, Guatemala, Honduras, México, Nicaragua, Panamá, Paraguay, Perú, República Dominicana y Uruguay. La cobertura del Perú corresponde al gobierno general.

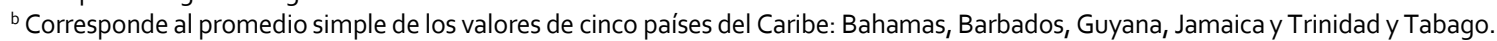

En el caso de la muestra de cinco países del Caribe de habla inglesa, el período de mayor dinamismo de la inversión pública tuvo lugar entre 2003 y 2007. El promedio simple del gasto público de capital de estos países aumentó del 2,8\% al 5,3\% del PIB en ese período, aunque este crecimiento se explica básicamente por la evolución positiva de la inversión pública en Guyana, Jamaica y Trinidad y Tabago, que coincidió con el auge del precio del petróleo y los minerales. A partir de 2008 y hasta 2016, el promedio del gasto de capital de los cinco países del Caribe muestra más bien una tendencia a la baja; luego se observa cierta recuperación en 2017 y llega a un valor medio del 3,4\% del PIB en 2019. 
Dada la alta correlación entre la inversión pública y el gasto del gobierno en asuntos económicos, a continuación se examina la evolución y composición de este último en cada subregión. Al igual que en el caso de la dinámica del gasto total de América Latina, el comportamiento de las erogaciones en asuntos económicos está más bien determinando por la evolución de los países sudamericanos (véase el gráfico 9). Desde 2007 se aprecia una recuperación de las erogaciones en asuntos económicos. Su crecimiento se acelera como respuesta a la gran recesión de 2008-2009, pero a partir de 2014 comienza una tendencia decreciente. Si bien esta evolución se observa tanto en la muestra de ocho países de América del Sur como en el grupo conformado por los seis países centroamericanos, México y la República Dominicana, es mucho más acentuada en la primera subregión.

Tanto en América del Sur como en la subregión conformada por los países centroamericanos, México y la República Dominicana, el sector más dinámico y con mayor participación en el gasto público destinado a los servicios económicos fue el transporte. En ese sector, el gasto como proporción del PIB se duplicó con creces en un período de diez años: creció desde el o,6\% del PIB en 2002 hasta llegar a un máximo del 1,4\% en 2012 en el promedio de los 16 países de América Latina. Luego, ese gasto disminuyó hasta alcanzar el 1,1\% del PIB en 2018, último año del que se dispone de información desagregada. En el caso de América del Sur, el sector de los combustibles y la energía fue otro en que el gasto aumentó entre 2008 y 2014, para luego ir retrocediendo, aunque esa evolución se explica principalmente por las políticas de subsidios a ese sector que se implementaron en la Argentina y el Ecuador. Un área en que la asignación de los recursos públicos cayó en ambas subregiones es la agricultura, la silvicultura, la pesca y la caza, en cuyo caso el gasto del gobierno central se redujo a la mitad en términos del PIB entre 2000 y 2018.

\section{Gráfico 9}

América Latina y el Caribe (16 países): gasto del gobierno central en asuntos económicos por grupo, 2000-2018 (En porcentajes del $P I B)$

A. América Latina (16 países)

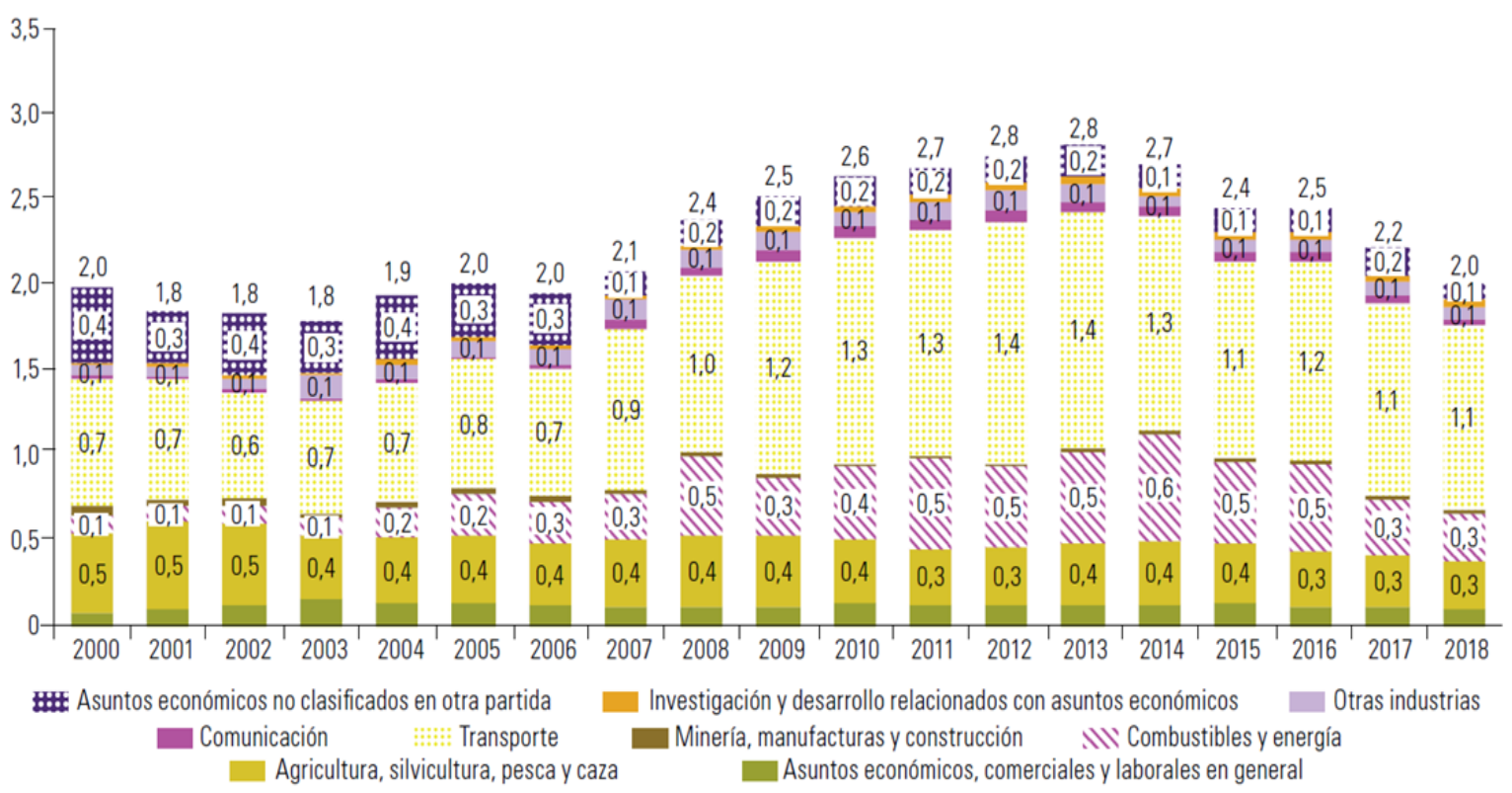


B. América del Sur (8 países)
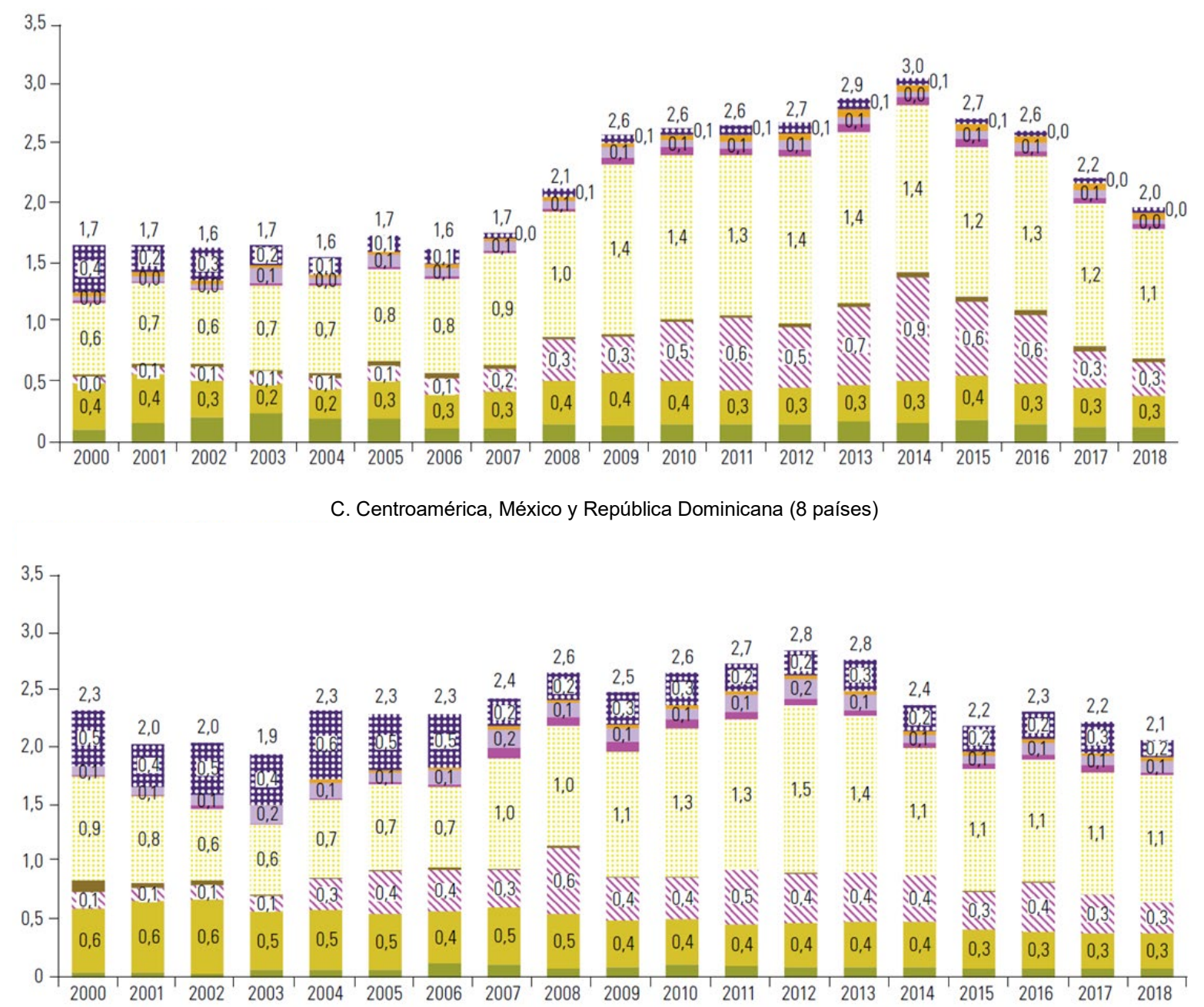

D. El Caribe (4 países)

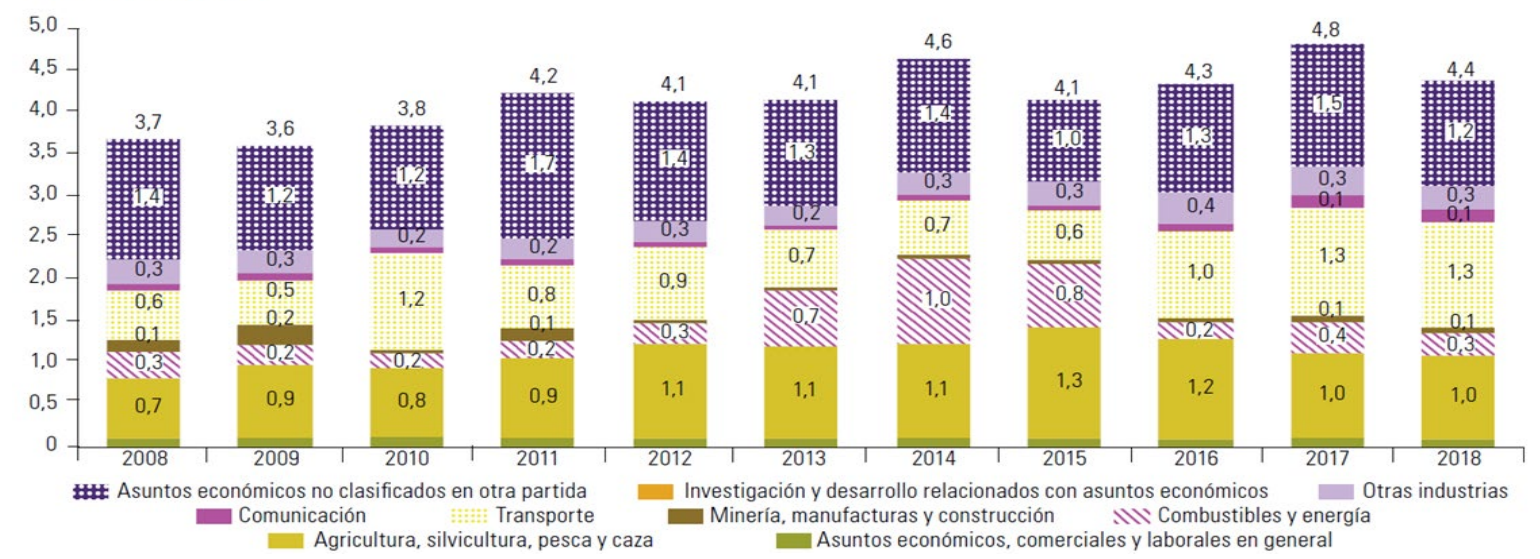

Fuente: Comisión Económica para América Latina y el Caribe (CEPAL), sobre la base de información oficial de los países.

${ }^{a}$ América Latina (gráfico A) corresponde al promedio simple de 16 países, que se dividen en dos grupos (gráficos B y C): ocho de América del Sur (Argentina, Brasil, Chile, Colombia, Ecuador, Paraguay, Perú y Uruguay) y ocho del grupo conformado por Centroamérica (Costa Rica, El Salvador, Guatemala, Honduras, Nicaragua y Panamá), México y la República Dominicana. En el caso del Caribe (gráfico D), se incluyen cuatro países: Bahamas, Guyana, Jamaica y Trinidad y Tabago. 
En cuanto al Caribe de habla inglesa, solo en cuatro países se dispone de información desagregada sobre el gasto destinado a la función de asuntos económicos durante el período 2008-2018. Según el promedio de estos países, el gasto en servicios económicos muestra una tendencia más bien creciente, aunque presenta un retroceso en 2018 debido a la aplicación de políticas de consolidación fiscal. A pesar de esa caída, en la muestra de los países caribeños se gasta más del doble que en los países latinoamericanos en esa función ( $4,4 \%$ y $2 \%$ del PIB, respectivamente).

El aumento del gasto en asuntos económicos en el Caribe durante esta última década se debe sobre todo a la ampliación de las erogaciones públicas en el área del transporte y de la agricultura, la silvicultura, la pesca y la caza. Al igual que en los países latinoamericanos, el gasto en transporte fue el más dinámico, dado que los recursos públicos destinados a este sector aumentaron más del doble en el último decenio y pasaron del $0,6 \%$ al 1,3\% del PIB entre 2008 y 2018. Sin embargo, a diferencia de los países latinoamericanos, donde las erogaciones asignadas a la agricultura se redujeron, el gasto promedio de los cuatro países del Caribe en este sector se incrementó del $0,7 \%$ al $1 \%$ del PIB; se destaca el mayor crecimiento de este tipo de gasto en Guyana.

Si bien el gasto del gobierno central en asuntos económicos correspondiente al promedio de los 16 países latinoamericanos fue del $2 \%$ del PIB en 2018, existen diferencias entre los países. Por ejemplo, en algunos se destina alrededor del $3 \%$ del PIB a esta función (Argentina, Chile, Nicaragua, Panamá y Perú), en tanto que en otros el gasto es del orden del 1\% del PIB o inferior (Brasil, Colombia, El Salvador y Guatemala). En el gasto promedio en asuntos económicos de América Latina, las erogaciones públicas en materia de transporte ascienden al 1,1\% del PIB, es decir, a la mitad del gasto en esta función del gobierno; le siguen en importancia el gasto en el sector de la agricultura, la silvicultura, la pesca y la caza, y el gasto en el sector de los combustibles y la energía, cada uno de los cuales representa el o,3\% del PIB ( $13 \%$ del gasto total en esa función). El resto de los sectores reciben menos del $5 \%$ del gasto destinado a asuntos económicos (véase el gráfico 10).

Aunque en la muestra de países del Caribe el gasto promedio en la función de asuntos económicos representa el $4,4 \%$ del PIB en 2018 , la diversidad entre los países es aún mayor. Por ejemplo, como se mencionó en la sección anterior, Guyana destaca con un nivel de casi el $9 \%$ del PIB, en tanto que en el resto de los países se asigna entre un $2,5 \%$ y un $3,2 \%$ del PIB a programas vinculados con el desarrollo económico. En el gasto promedio destinado a asuntos económicos de los países caribeños también sobresale el gasto en transporte, que alcanza el 1,3\% del PIB, pero le sigue de cerca el gasto en agricultura, silvicultura, pesca y caza, que representa el 1\%; esto significa que, en conjunto, estos dos sectores reciben más del $50 \%$ de los recursos dirigidos a esa función.

La composición de las erogaciones en asuntos económicos presenta algunas similitudes y diferencias entre los países de la región. Si bien en casi todos los casos el sector que absorbe la mayor cantidad de recursos públicos es el transporte, que abarca los gastos relacionados con carreteras, ferrocarriles, sistemas de transporte aéreo, marítimo y otros, en algunos países predomina el gasto en otras áreas económicas. Por ejemplo, las erogaciones del gobierno central en programas del sector de los combustibles y la energía son superiores a las del sector transporte en la Argentina, la República Dominicana, Trinidad y Tabago y El Salvador. En este último, por su parte, y al igual que ocurre en el Brasil y Guyana, el gasto en programas del gobierno central relacionados con la agricultura, la silvicultura, la pesca y la caza adquiere mayor importancia que el transporte. 


\section{Gráfico 10}

América Latina y el Caribe (20 países): distribución del gasto en asuntos económicos del gobierno central por país y por grupo, 2018

(En porcentajes del gasto en asuntos económicos)

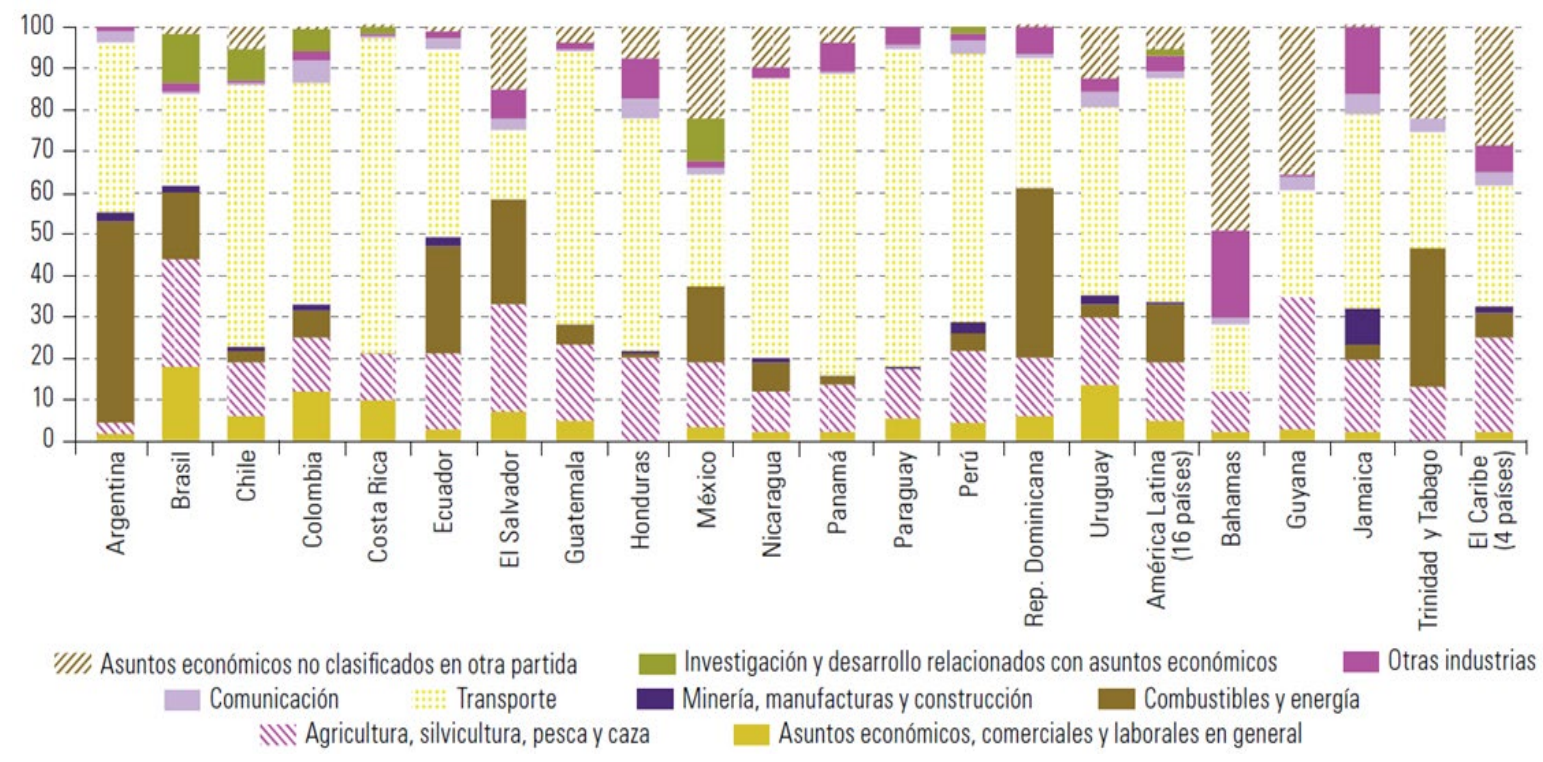

Fuente: Comisión Económica para América Latina y el Caribe (CEPAL), sobre la base de información oficial de los países. a Los datos de Guyana y Panamá corresponden a 2017. La cobertura del Perú corresponde al gobierno general.

\section{El gasto en asuntos económicos según subsector en coberturas institucionales más amplias}

En el recuadro 1 se realizó un análisis de la clasificación funcional del gasto considerando coberturas institucionales más amplias en ocho países con información disponible (Argentina, Brasil, Colombia, Costa Rica, El Salvador, Panamá, Paraguay y el Perú a). En este recuadro se profundiza el análisis del gasto en servicios económicos por subsector de actividad en estos mismos países, ya sea a nivel de gobierno general o de sector público según el caso.

El gasto público en asuntos económicos como porcentaje del PIB se incrementa al pasar de una cobertura de gobierno central a otra más amplia que incluye a los gobiernos intermedios y locales y otras entidades públicas, aunque la magnitud de este aumento varía entre países. El alza más relevante corresponde a El Salvador, pero las diferencias también son importantes en Colombia y en Argentina. En el caso del primero, el gasto en asuntos económicos del sector público salvadoreño supera en 2,7 puntos del PIB al gasto que consideraba únicamente al gobierno central, en tanto que en Colombia las erogaciones vinculadas al desarrollo económico aumentan en 2,3 puntos del PIB cuando en la cobertura institucional se considera no solo al gobierno central sino también a los niveles subnacionales de gobierno.

En Argentina, el gasto en esa función de gobierno es mayor que en los demás países, ya que alcanza un valor que se aproxima al $5 \%$ del PIB. Le siguen, en orden de importancia, El Salvador, Panamá, Perú y Colombia, donde dicho gasto se ubica entre $3,2 \%$ y $3,9 \%$ del PIB. Por último, con cifras cercanas al 2,5\% del PIB se hallan Paraguay y Costa Rica, en tanto que en Brasil estas erogaciones apenas llegan al 1,6\% del PIB. 


\section{Gráfico 1}

América Latina (8 países): gasto en asuntos económicos por subsector según cobertura institucional, alrededor de 2018 (En porcentajes del PIB)

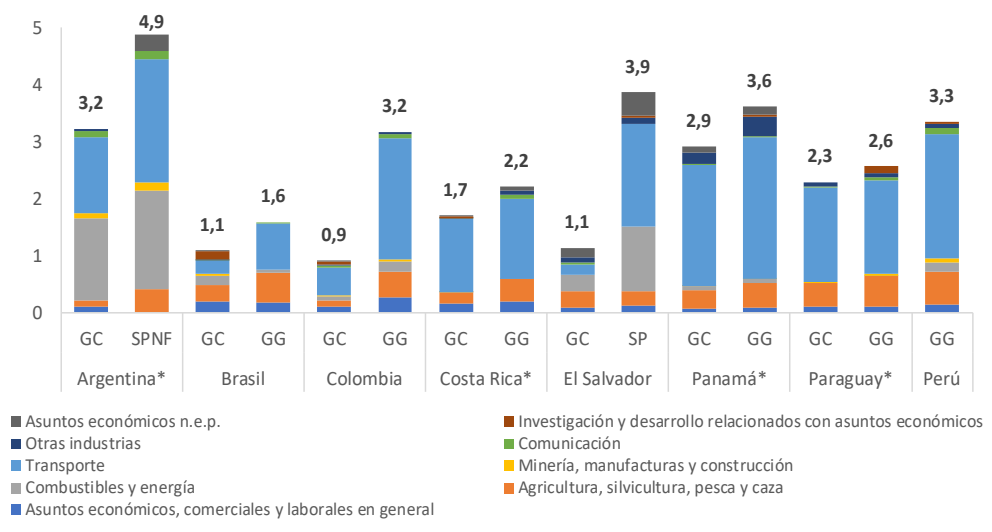

Fuente: Comisión Económica para América Latina y el Caribe (CEPAL), sobre la base de información oficial de los países.

Nota: GC significa gobierno central, GG significa gobierno general, SPNF significa sector público no financiero y SP significa sector público.

* Los datos de la Argentina, Panamá y el Paraguay corresponden a 2017, y los de Costa Rica a 2016.

a En el caso del Perú, la serie es la misma que en las otras secciones del documento, pues solo se dispone de datos relativos a la cobertura de gobierno general.

Al considerar coberturas institucionales más amplias, el gasto en asuntos económicos aumenta en ciertas ramas de la actividad económica, modificando en algunos países la distribución de las prioridades del gasto vinculado al desarrollo económico según sectores.

En todos los países, con excepción de El Salvador, la cobertura más amplia muestra incrementos en el gasto dirigido a Agricultura, silvicultura, pesca y caza. El gasto público en este sector alcanza un valor promedio de 0,5\% del PIB cuando se incluye información de los niveles subnacionales de gobierno y otros organismos estatales.

En cuanto a las erogaciones relacionadas con el sector combustible y energía, cuando se amplía la cobertura institucional, se aprecia un alza importante en El Salvador, en parte por el gasto de la Comisión Ejecutiva Hidroeléctrica del Río Lempa, como se mencionó en el recuadro 1. También se registran aumentos en Argentina y Colombia, pero en magnitudes más pequeñas.

En general, el gasto público vinculado con el sector transporte es el que más aumenta al comparar la cobertura del gobierno central con una más amplia, debido al rol que desempeñan los gobiernos subnacionales y otras entidades públicas en este tipo de erogaciones. En promedio, la proporción de recursos destinados al gasto público en transporte se ubica en el $60 \%$ del gasto total en asuntos económicos en la muestra de ocho países latinoamericanos con información disponible. Así, el sector transporte pasa a ser el de mayor prioridad en la asignación de recursos públicos para el desarrollo económico en los ocho países analizados. En contraste, en el análisis que solo incluía al gobierno central, era más significativo el gasto en combustible y energía en Argentina; el gasto en agricultura en Brasil o en esos dos sectores en El Salvador.

De esta forma, el gasto en transporte se acerca o supera el $2 \%$ del PIB en Argentina, Colombia, El Salvador, Panamá y Perú; se ubica en un nivel intermedio que ronda el 1,5\% del PIB en Costa Rica y Paraguay; en tanto que en Brasil este gasto se sitúa en $0,8 \%$ del PIB.

En los restantes sectores que forman parte de la función asuntos económicos, los cambios en el gasto público cuando se considera una cobertura de gobierno más amplia son de magnitudes poco significativas.

Fuente: Elaboración propia sobre la base de la CEPAL.

Por otro lado, resulta interesante examinar el gasto público cruzando la clasificación económica y la funcional. Esto permite tener una perspectiva más completa y precisa sobre el destino de la inversión pública, ya que esta no solo se dirige a la función de asuntos económicos, sino que también abarca otras funciones, como la vivienda, la educación, la salud y otras. Además, el gasto en asuntos económicos no solo incluye el gasto de capital, sino que también comprende erogaciones corrientes, como la compra de bienes y servicios, el pago de remuneraciones y las transferencias corrientes. Sin embargo, no es fácil 
acceder a esta información respecto de todos los países, por lo que el análisis que sigue se concentra en una muestra de diez países de la región que publican datos detallados sobre el período comprendido entre 2011 y 2018. El propósito de este análisis es determinar cuáles han sido los sectores más afectados por el recorte de la inversión pública en los últimos años.

En el gráfico 11 se observa la composición promedio del gasto en una muestra de diez países de América Latina, según función de gobierno y clasificación económica. Así, destaca que cerca del 90\% o más del gasto en servicios públicos generales, defensa, orden público y seguridad, protección social, salud y educación corresponde a gasto corriente, mientras que el gasto de capital tiene más importancia en las funciones relacionadas con los asuntos económicos y la vivienda. En efecto, más del $40 \%$ del gasto de capital se destina a la función de asuntos económicos, casi un $20 \%$ a la vivienda y los servicios comunitarios, y poco más del 10\% corresponde a educación. Le siguen en orden de importancia los servicios públicos generales, la protección social, la protección del medio ambiente y la salud, con un peso relativo de entre el $5 \%$ y el $7 \%$ del gasto total de capital; el resto se distribuye entre defensa, orden público y seguridad, y actividades recreativas, cultura y religión.

\section{Gráfico 11}

América Latina y el Caribe (10 países)a: gasto del gobierno central según clasificación funcional y económica, 2018 (En porcentajes del PIB)

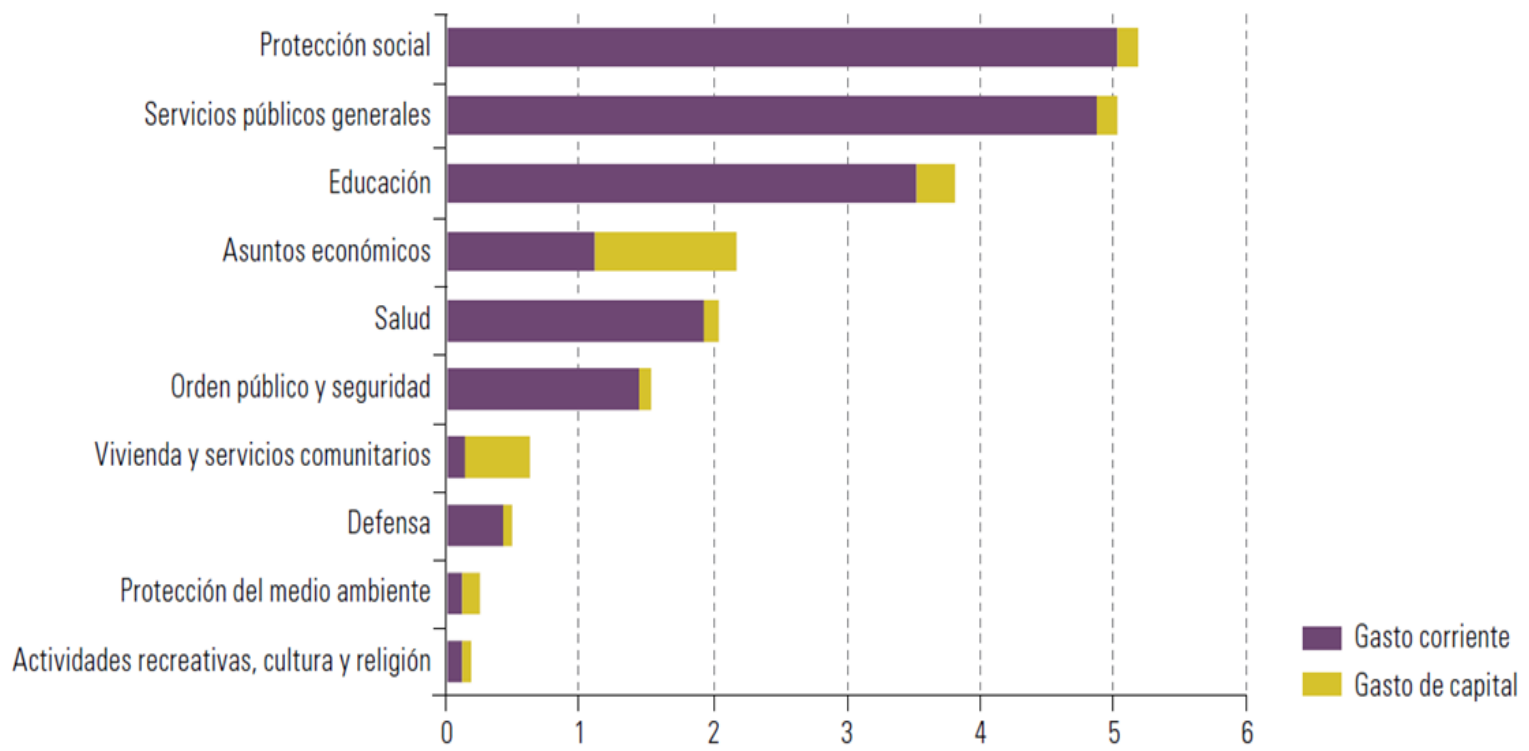

Fuente: Comisión Económica para América Latina y el Caribe (CEPAL), sobre la base de información oficial de los países.

a Corresponde al promedio simple de los valores de 10 países de América Latina: Argentina, Brasil, Chile, Costa Rica, Guatemala, México, Panamá, Perú, República Dominicana y Uruguay. La cobertura del Perú corresponde al gobierno general.

Como se mostró anteriormente, a partir de 2014 el gasto de capital muestra una tendencia decreciente en un contexto de políticas de consolidación fiscal, bajo crecimiento de la actividad económica y mayor incertidumbre mundial. En el promedio de los diez países latinoamericanos respecto de los cuales se dispone de información sobre la clasificación cruzada del gasto, se observa que el recorte del gasto de capital afectó todas las funciones del gobierno central, con la excepción de los programas de protección social. Estos tienen un componente muy bajo de inversión pública, ya que el $97 \%$ de las erogaciones en esta función corresponde a gasto corriente. Debido a la importancia de la inversión pública en el gasto en asuntos económicos, esta función de gobierno explica más de la mitad de la caída de los gastos de capital de los últimos años. Las políticas vinculadas con la vivienda y la educación también se vieron afectadas por el ajuste de la inversión pública (véase el gráfico 12). 
Gráfico 12

América Latina y el Caribe (10 países) ${ }^{a}$ : gasto de capital del gobierno central por función, 2011-2018 (En porcentajes del PIB)

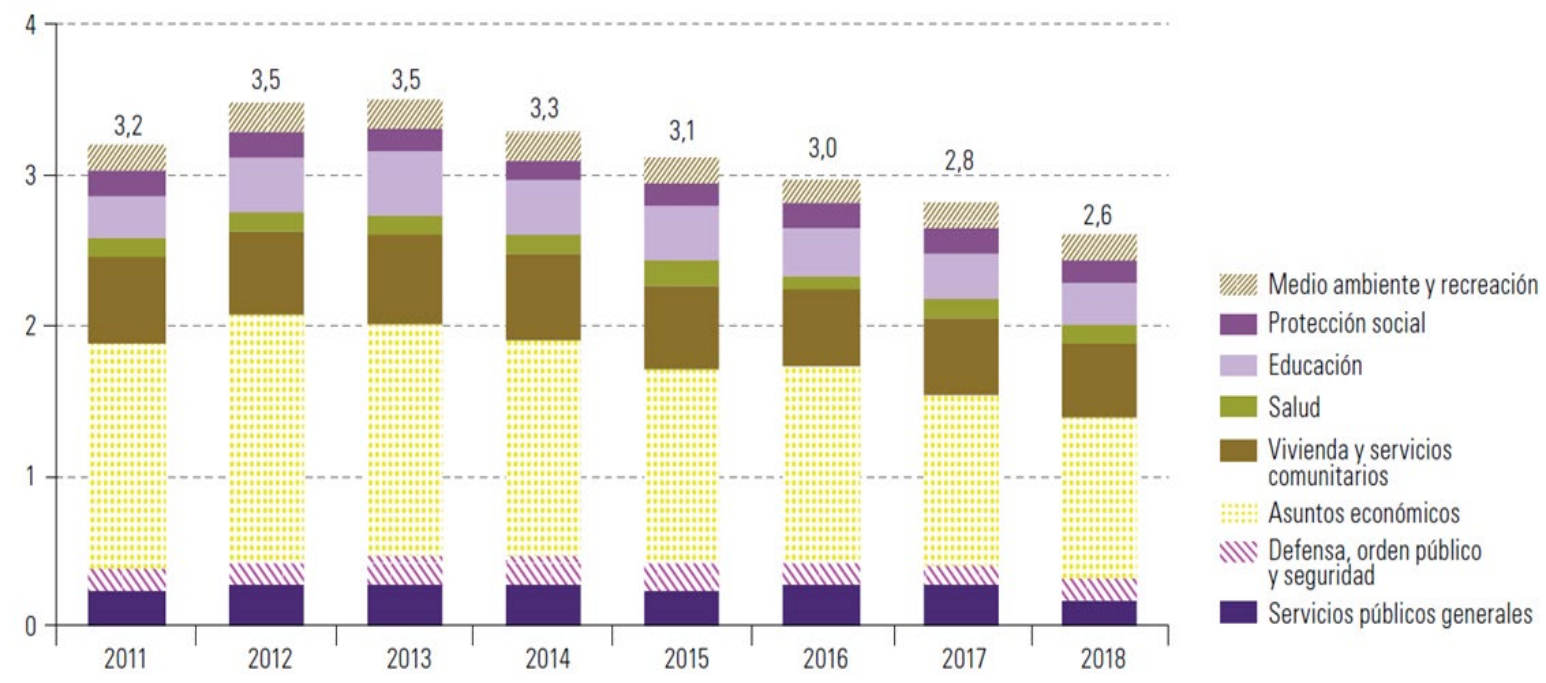

Fuente: Comisión Económica para América Latina y el Caribe (CEPAL), sobre la base de información oficial de los países.

a Corresponde al promedio simple de los valores de 10 países de América Latina: Argentina, Brasil, Chile, Costa Rica, Guatemala, México, Panamá, Perú, República Dominicana y Uruguay. La cobertura del Perú corresponde al gobierno general.

No obstante, una vez más es importante señalar que hay diferencias entre los países en cuanto al nivel del gasto de capital, el grado de ajuste y las áreas en que la inversión pública se recortó en mayor medida (véase el gráfico 13). Entre los gobiernos centrales cuyo gasto de capital fue mayor se encuentran Panamá y el Perú, con $5,6 \%$ y $4,7 \%$ del PIB en 2018 , respectivamente. En esos países, las funciones económicas reciben cerca del $40 \%$ o más del gasto de capital, pero también es importante la inversión pública destinada a la infraestructura educativa y otros gastos de capital en la función de educación (en ambos países), así como la inversión pública en viviendas y servicios comunitarios (Panamá) y en protección del medio ambiente (Perú). Chile es otro caso en que las erogaciones públicas de capital superan al valor promedio de la muestra de países de la región: el gasto de capital del gobierno central de ese país representó el $3,7 \%$ del PIB. Allí, además de dar prioridad a la inversión pública en asuntos económicos, también se destacan los fondos públicos destinados a financiar el gasto de capital en las funciones de defensa y protección social.

En el otro extremo, los países cuyo gobierno central ha hecho el menor gasto de capital son el Brasil, la Argentina y Costa Rica, aunque en los dos primeros son relevantes las inversiones de los gobiernos intermedios, que no están incluidas en esta medición.

En todos los países analizados, la función de asuntos económicos es la que tiene mayor peso en el gasto total de capital del gobierno central, con la excepción de Guatemala, donde la inversión pública en vivienda y servicios comunitarios adquiere mayor preponderancia, ya que llega al 1,3\% del PIB en 2018 y representa el $53 \%$ del gasto total de capital. 
Gráfico 13

América Latina (10 países): composición del gasto de capital según función del gobierno central y gasto máximo del período, por país, 2011-2018 (En porcentajes del PIB)

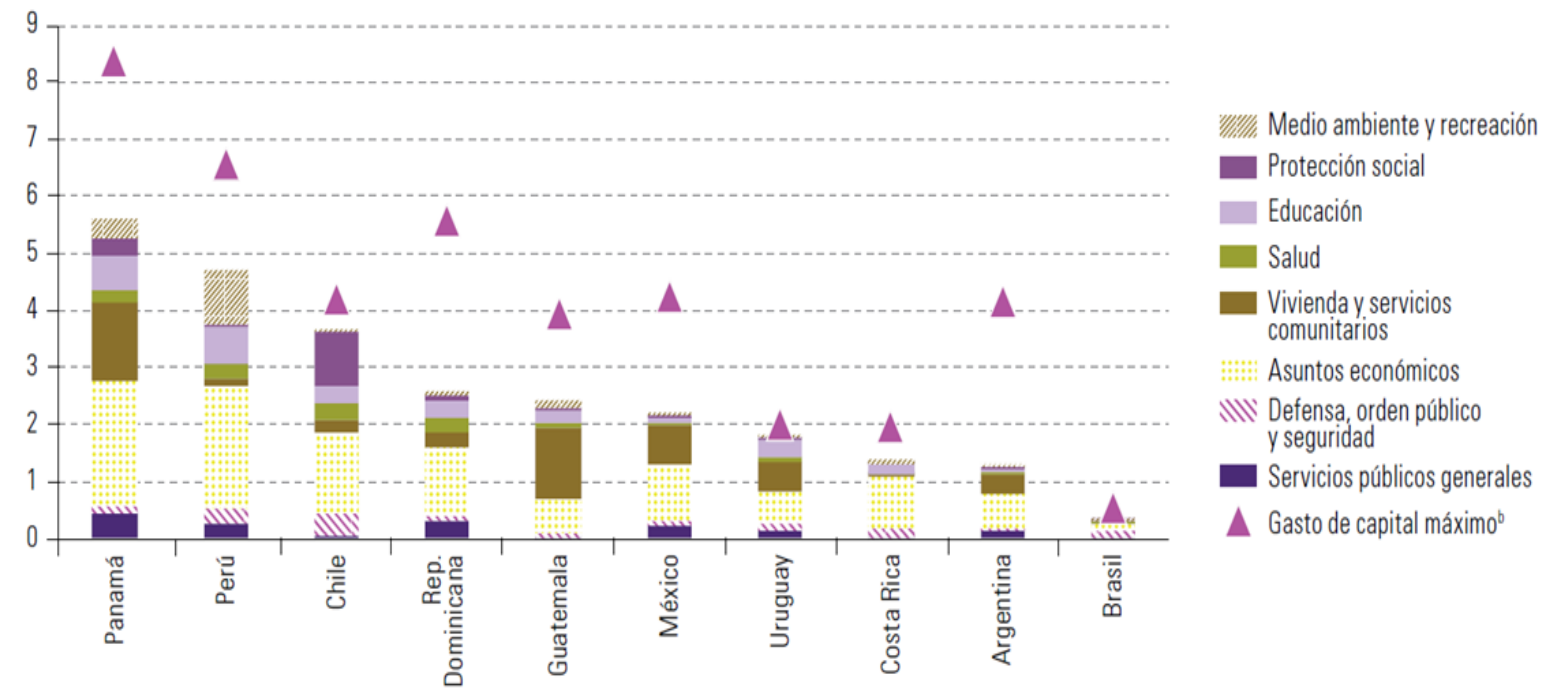

Fuente: Comisión Económica para América Latina y el Caribe (CEPAL), sobre la base de información oficial de los países.

a La composición del gasto de capital corresponde a 2018; el gasto máximo corresponde al período 2011-2017.

b El gasto máximo de capital se alcanza en 2014 en la Argentina y el Brasil, en 2015 en Chile, en 2017 en Costa Rica, en 2011 en Guatemala, en 2016 en México, en 2013 en Panamá y el Perú, en 2012 en la República Dominicana y en 2011 en el Uruguay.

La contracción del gasto de capital a nivel de los gobiernos centrales durante los últimos años también varía de país en país (véase el gráfico 14). En algunos, como la Argentina, la República Dominicana y Panamá, la caída rondó los 3 puntos del PIB, aunque en el caso de Panamá se parte de una base de comparación bastante más alta (véase el gráfico 13). En otros países, como México, el Perú y Guatemala, el ajuste del gasto de capital fue de entre 1,5 y 2,1 puntos porcentuales del PIB, en tanto que en los demás (Costa Rica, Chile, Brasil y Uruguay), el recorte fue mucho más pequeño.

Claramente, los programas más afectados por el recorte de la inversión pública de los últimos años han sido los que tienen relación con el desarrollo económico, ya que la disminución del gasto de capital en asuntos económicos explica, en promedio, casi dos tercios de la contracción total del gasto de capital de los gobiernos centrales en la muestra de diez países de América Latina. Las caídas en esta función son más significativas en Panamá, la República Dominicana, la Argentina, Guatemala y México. La disminución del gasto de capital también se vio reflejada en una menor inversión pública en vivienda, sobre todo en estos tres últimos países. En algunos casos, como la República Dominicana, Chile y el Uruguay, el ajuste de la inversión pública también repercutió en un menor gasto de capital destinado a la educación, mientras que en otros, como Panamá y el Perú, se dio una menor prioridad a la inversión pública dirigida a defensa, orden público y seguridad. 
Gráfico 14

América Latina (10 países): variación del gasto de capital según función del gobierno central, por país, 2011-2018 (En puntos porcentuales del PIB)

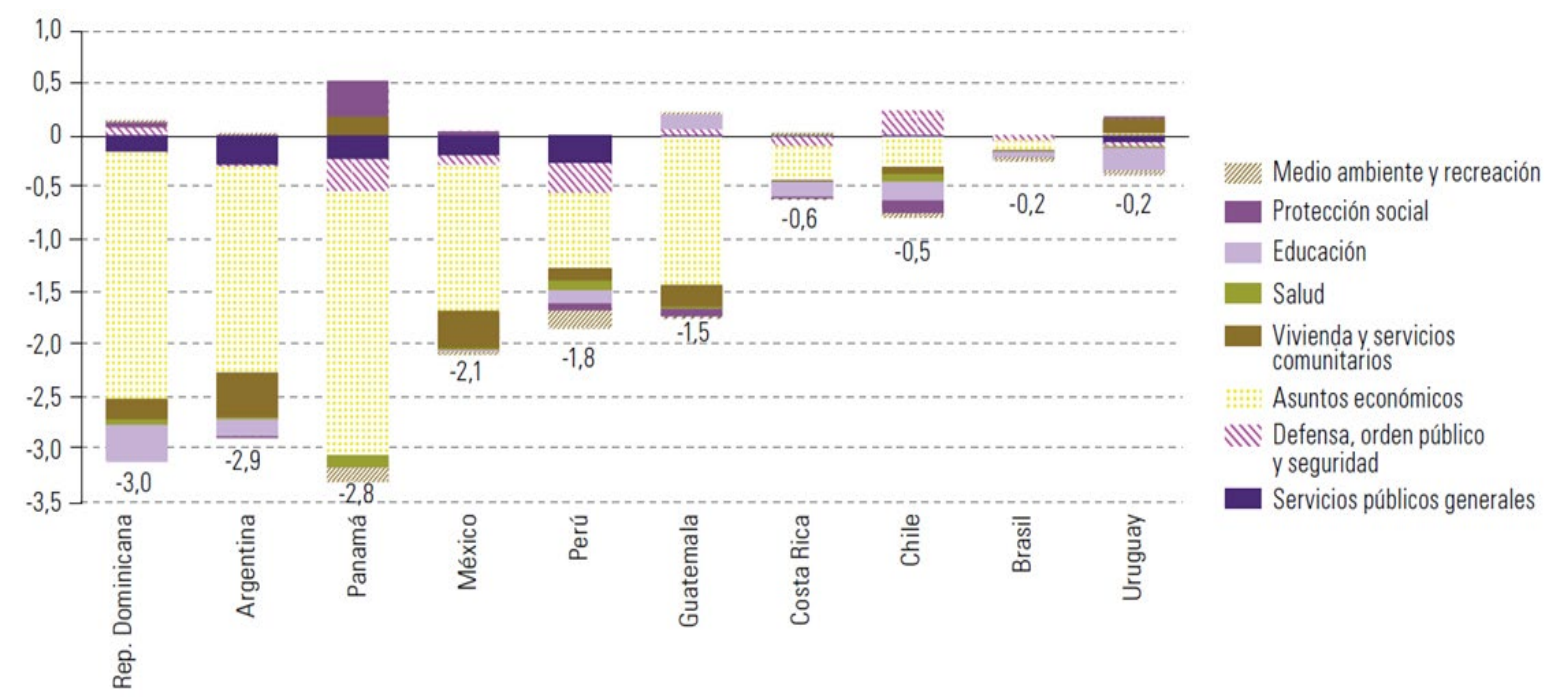

Fuente: Comisión Económica para América Latina y el Caribe (CEPAL), sobre la base de información oficial de los países.

a La variación del gasto de capital se determina comparando el gasto de 2018 con el gasto máximo de cada país en el período 2011-2017. El gasto máximo se alcanzó en 2014 en la Argentina y el Brasil, en 2015 en Chile, en 2017 en Costa Rica, en 2011 en Guatemala, en 2016 en México, en 2013 en Panamá y el Perú, en 2012 en la República Dominicana y en 2011 en el Uruguay.

\section{América Latina (10 países): variación del gasto de capital del gobierno central en asuntos económicos, por grupo y por país, 2011-2018 \\ (En puntos porcentuales del PIB)}

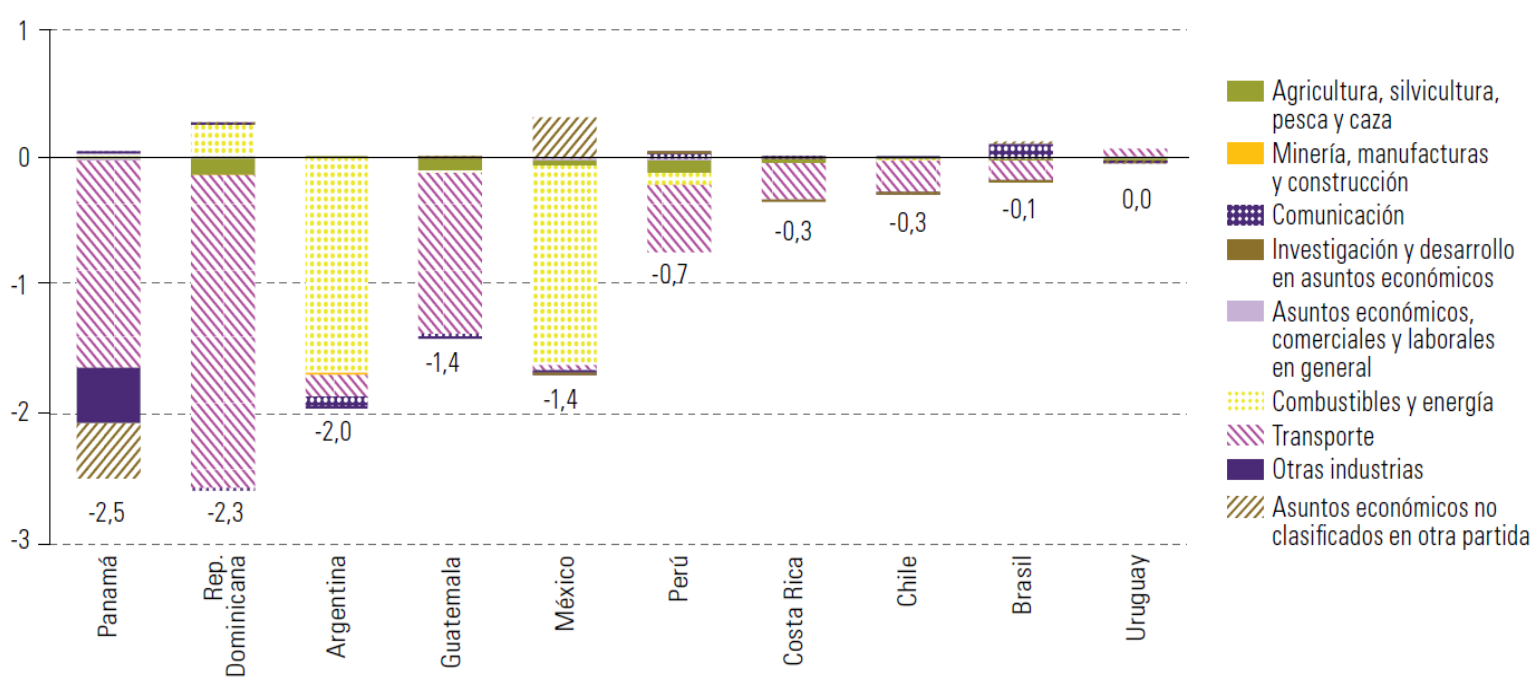

Fuente: Comisión Económica para América Latina y el Caribe (CEPAL), sobre la base de información oficial de los países.

${ }^{a}$ La variación del gasto de capital se determina comparando el gasto de 2018 con el gasto máximo de cada país en el período 2011-2017. El gasto máximo se alcanzó en 2014 en la Argentina y el Brasil, en 2015 en Chile, en 2017 en Costa Rica, en 2011 en Guatemala, en 2016 en México, en 2013 en Panamá y el Perú, en 2012 en la República Dominicana y en 2011 en el Uruguay. 
Por último, resulta interesante conocer cuáles fueron los sectores de la economía donde la inversión pública se ajustó en mayor medida, sobre todo en los países en que el gasto de capital destinado a la función de asuntos económicos se redujo más (véase el gráfico 15). En la mayoría de los casos examinados predominó el recorte del gasto de capital en el sector transporte, a excepción de la Argentina y México, donde la mayor reducción de este tipo de gasto se observó en el sector de los combustibles y la energía. Además, algunos gobiernos, como los de la República Dominicana, Guatemala y el Perú, disminuyeron el gasto de capital destinado a los programas vinculados con la agricultura, la silvicultura, la pesca y la caza, aunque en una magnitud menor que en el área del transporte. 



\section{Conclusiones y reflexiones finales}

El nuevo escenario creado por la pandemia del COVID-19 se suma al complejo contexto que ya enfrentaban los países de América Latina y el Caribe desde hace unos años, caracterizado por una creciente incertidumbre, desaceleración económica, aumento del desempleo y retroceso en los índices de pobreza extrema. A esto se agrega también el fuerte descenso en los precios de las materias primas, en especial del petróleo, que repercute principalmente en los países productores de la región. Este conjunto de factores reduce los ingresos fiscales y el margen para aumentar el gasto público y aplicar las políticas necesarias para dar respuesta a esta nueva y compleja situación.

Además, dado el bajo crecimiento de los últimos años, la pérdida de espacio fiscal y la menor disponibilidad de financiamiento, en los países de la región se cuenta con una menor capacidad para enfrentar este escenario en comparación con las herramientas que se tuvieron para responder a la crisis mundial de 2008-2009.

Así, a los desafíos habituales de política fiscal que los países de la región deben enfrentar a fin de cumplir con los ODS ahora se suma la necesidad de implementar políticas activas para enfrentar la pandemia del COVID-19 y mitigar los efectos económicos y sociales que esta genera. En virtud de esto, es muy importante que el Estado actúe a través de la política fiscal, en general, y de los programas de gasto público, en particular, de manera que los gobiernos puedan asignar mayores recursos a la atención de la salud, mejorar la eficiencia del gasto, resguardar las fuentes de trabajo y los ingresos de las familias y, sobre todo, proteger a la población más vulnerable.

En efecto, en los países de la región ya se han tomado medidas frente a la pandemia, y estas acciones tendrán un impacto sobre el gasto público y los balances fiscales que ya venían deteriorándose. En ese sentido, un aporte importante para que los gobiernos tomen decisiones sobre reasignar partidas o aumentar el gasto en ciertos programas es contribuir con mayor trasparencia fiscal e información comparable entre los países sobre las principales áreas a las que se destinan los recursos públicos.

Es por ello que en el presente estudio se analizó la evolución del gasto público y se examinó de manera detallada cuáles han sido las prioridades durante los últimos años en los países de la región. 
Como se vio en la sección II, si bien a partir de 2018 el gasto público promedio a nivel del gobierno central de los países latinoamericanos se redujo como resultado de los procesos de consolidación fiscal, dicho gasto se mantiene bastante por encima de los valores de comienzo del milenio. Este mayor nivel de gasto se debe a que, en el período 2000-2018, en los países de América Latina se priorizó el gasto social y aumentó la importancia relativa del gasto destinado al orden público y la seguridad. Por otra parte, se redujo el peso del gasto destinado a las funciones de servicios públicos generales, defensa y asuntos económicos respecto del gasto total. En los países sudamericanos, en promedio, casi un $60 \%$ del gasto total se destinó a funciones sociales, en tanto que en el grupo integrado por los países de Centroamérica, México y la República Dominicana, el gasto social representó casi la mitad del total en 2018.

En la muestra de cinco países del Caribe de habla inglesa, el promedio del gasto del gobierno central presentó, en general, un nivel más estable durante el período, aunque en 2018 se contrajo en respuesta a las políticas de ajuste fiscal. En estos países también se observó un cambio a favor de las funciones sociales en la asignación del gasto a los distintos propósitos del gobierno, tanto si el gasto se mide en relación con el PIB como si se mide en relación con en el gasto total (en cuyo caso el gasto social corresponde al $43 \%$ del total. Además, gracias a la importante reducción de las erogaciones destinadas a la función de los servicios públicos generales, que ocurrió como consecuencia de los programas de reestructuración de la deuda en algunos países, de la disminución del pago de intereses y de los procesos de ajuste del gasto, también aumentó el peso relativo del gasto destinado a los asuntos económicos y al orden público y la seguridad.

Sin embargo, como se analizó en el documento, estas tendencias y promedios regionales y subregionales esconden la heterogeneidad que hay en cuanto a la situación de cada país.

Por otra parte, dado que la inversión pública desempeña un rol clave en el crecimiento económico y en el logro de los Objetivos de la Agenda 2030, resulta importante contar con información acerca de en qué funciones y sectores se ha priorizado la inversión y en cuáles se ha ajustado más el gasto de capital en los últimos años.

En ese sentido, y dada la alta correlación que existe entre la inversión pública y el gasto del gobierno en asuntos económicos, se examinó la evolución y la composición de este último. En los países latinoamericanos, el sector de los servicios económicos que fue más dinámico y tuvo mayor participación en el gasto público fue el transporte, cuyo gasto como proporción del PIB se duplicó con creces entre 2002 y 2012, momento a partir del cual se fue recortando año a año. En cambio, el gasto en agricultura, silvicultura, pesca y caza mostró una tendencia decreciente en todo el período analizado y se redujo a la mitad de su valor inicial. Asimismo, en América del Sur, los recursos asignados a los combustibles y la energía evolucionaron de forma similar a los del sector del transporte, aunque su peso en el total del gasto fue bastante menor.

En los países del Caribe de habla inglesa, la tendencia del gasto en servicios económicos fue más bien creciente, aunque presentó un retroceso en 2018 debido a las políticas de consolidación fiscal. A pesar de esta caída, en los países caribeños se gastó más del doble de lo que se gastó en los países latinoamericanos en esta función: el $4,4 \%$ frente al $2 \%$ del PIB, respectivamente. Este aumento del gasto en asuntos económicos en el Caribe durante 2008-2018 se debió principalmente a la ampliación de las erogaciones públicas tanto en el área del transporte como en la de la agricultura, la silvicultura, la pesca y la caza, que juntas representaron más del $50 \%$ de los recursos dirigidos a esta función.

En definitiva, en un entorno de bajo crecimiento, desaceleración e incertidumbre mundial al que ahora se suman los efectos de la pandemia del COVID-19, la caída de la inversión pública en la mayoría de los países de la región es perjudicial y no contribuye a retomar la senda de crecimiento, resguardar el empleo y proteger a la población más vulnerable. Como se vio en el estudio, esto se 
debe a que, tal como demuestran los datos empíricos, los multiplicadores del gasto de capital son mayores que los del gasto corriente, y a que predomina una relación de complementariedad entre la inversión pública y la privada.

En la situación actual, la prioridad de los países es reforzar los sistemas sanitarios y hacer frente a los desafíos sociales y económicos de esta pandemia, lo que conlleva a una mayor presión sobre el gasto público. No obstante, a mediano plazo y para seguir la ruta propuesta en la Agenda 2030 a los efectos de alcanzar los ODS, la prioridad de los gobiernos debería centrarse no solo en proteger el gasto social, sino también en revitalizar la inversión pública. 



\section{Bibliografía}

Auerbach, A. y Y. Gorodnichenko (2013), "Output spillovers from fiscal policy", American Economic Review, vol. 103, $\mathrm{N}^{\circ}$ 3, Nashville, Asociación Estadounidense de Economía.

(2012), "Measuring the output responses to fiscal policy", American Economic Journal: Economic Policy, vol. 4, № 2, Nashville, Asociación Estadounidense de Economía.

Buchanan, J. y R. Musgrave (1999), Public Finance and Public Choice: Two Contrasting Visions of the State, Cambridge, MIT Press.

CEPAL (Comisión Económica para América Latina y el Caribe) (2019a), Informe de avance cuatrienal sobre el progreso y los desafíos regionales de la Agenda 2030 para el Desarrollo Sostenible en América Latina y el Caribe (LC/FDS.3/3/Rev.1), Santiago, junio.

(2019b), Panorama Social de América Latina, 2019 (LC/PUB.2019/22-P/Rev.1), Santiago.

(2019C), Balance Preliminar de las Economías de América Latina y el Caribe, 2019 (LC/PUB.2019/25-P), Santiago.

(2019d), Balance Preliminar de las Economías de América Latina y el Caribe, 2018 (LC/PUB.2019/1-P), Santiago.

(2019e), La Agenda 2030 y los Objetivos de Desarrollo Sostenible: una oportunidad para América Latina y el Caribe (LC/G.2681-P/Rev.3), Santiago, julio.

(2018), Panorama Fiscal de América Latina y el Caribe, 2018 (LC/PUB.2018/4-P), Santiago. (2015), Estudio Económico de América Latina y el Caribe, 2015 (LC/G.2645-P), Santiago.

Christiano, L., M. Eichenbaum y S. Rebelo (2011), "When is the government spending multiplier large?", Journal of Political Economy, vol. 119, No 1, Chicago, University of Chicago Press, febrero.

Coenen, G., R. Straub y M. Trabandt (2013), "Gauging the effects of fiscal stimulus packages in the euro area", Journal of Economic Dynamics and Control, vol. 37, № 2, Amsterdam, Elsevier.

Fanelli, J. (2013), "Política fiscal e inversión: un enfoque sistémico y de crecimiento inclusivo", serie Macroeconomía del Desarrollo, № 127 (LC/L.3556), Santiago, Comisión Económica para América Latina y el Caribe (CEPAL).

FMI (Fondo Monetario Internacional) (2014a), "Is it time for an infrastructure push? The macroeconomic effects of public investment", World Economic Outlook: Legacies, Clouds, Uncertainties, Washington D. C., octubre. (2014b), Manual de Estadísticas de Finanzas Públicas 2014, Washington D. C.

Furceri, D. y B. Li (2017), "The macroeconomic (and distributional) effects of public investment in developing economies", IMF Working Paper, $\mathrm{N}^{\circ}$ 17/217, Washington D. C., Fondo Monetario Internacional (FMI), octubre.

González-García, J., A. Lemus y M. Mrkaic (2013), "Fiscal multipliers in the ECCU", IMF Working Paper, № 13/117, Washington D. C., Fondo Monetario Internacional (FMI). 
Huidrom, R. y otros (2019), "Why do fiscal multipliers depend on fiscal positions?", CAMA Working Paper, No 28/2019, Canberra, Universidad Nacional Australiana, marzo.

Ilzetzki, E., E. Mendoza y C. Végh (2013), "How big (small?) are fiscal multipliers?", Journal of Monetary Economics, vol. 6o, $\mathrm{N}^{\circ}$ 2, Amsterdam, Elsevier.

Izquierdo, A. y otros (2019), "Is the public investment multiplier higher in developing countries? An empirical exploration", IMF Working Paper, No 19/289, Washington D. C., Fondo Monetario Internacional (FMI), diciembre.

James, S. (2013), "Effectiveness of tax and non-tax incentives and investments: evidence and policy implications", Washington D. C., Banco Mundial.

Jiménez, J. y A. Podestá (2009), "Inversión, incentivos fiscales y gastos tributarios en América Latina", serie Macroeconomía del Desarrollo, No 77 (LC/L.3004-P), Santiago, Comisión Económica para América Latina y el Caribe (CEPAL).

Martner, R., A. Podestá e I. González (2013), "Políticas fiscales para el crecimiento y la igualdad", serie Macroeconomía del Desarrollo, № 138 (LC/L.3716), Santiago, Comisión Económica para América Latina y el Caribe (CEPAL), octubre.

Martner, R. y V. Tromben (2005), "Opciones para enfrentar el sesgo anti-inversión pública", serie Gestión Pública, No 50, Santiago, Instituto Latinoamericano y del Caribe de Planificación Económica y Social/Comisión Económica para América Latina y el Caribe (ILPES/CEPAL).

Musgrave, R. y P. Musgrave (1991), Hacienda pública teórica y aplicada, Nueva York, McGraw-Hill.

Naciones Unidas (2002), "Clasificaciones de gastos por finalidades", Informes Estadísticos: Serie M, No 84, Nueva York, febrero.

OPS (Organización Panamericana de la Salud) (2019), Indicadores básicos 2019: tendencias de la salud en las Américas, Washington D. C.

Riera-Crichton, D., C. Vegh y G. Vuletin (2015), "Fiscal multipliers in Latin America", Santiago, Comisión Económica para América Latina y el Caribe (CEPAL), inédito.

Spilimbergo, A., M. Schindler y S. Symansky (2009), "Fiscal multipliers", Staff Position Note, № 2009/11, Washington D. C., Fondo Monetario Internacional (FMI).

Stiglitz, J. (2000), La economía del sector público, Barcelona, Antoni Bosch Editor. 


\title{
Serie
}

\section{E P A L Macroeconomía del Desarrollo}

\section{Números publicados}

\author{
Un listado completo así como los archivos pdf están disponibles en \\ www.cepal.org/publicaciones
}

214. Gasto público para impulsar el desarrollo económico e inclusivo y lograr los Objetivos de Desarrollo Sostenible, Andrea Podestá (LC/TS.2020/123), 2020.

213. Explorando sinergias entre la cooperación tributaria internacional y los desafíos tributarios latinoamericanos en tiempos del COVID19, Juan Pablo Jiménez, José Antonio Ocampo, Andrea Podestá, María Fernanda Valdés (LC/TS.2020/104), 2020.

212. Los sistemas de pensiones en América Latina: institucionalidad, gasto público y sostenibilidad financiera en tiempos del COVID-19, Alberto Arenas de Mesa (LC/TS.2020/99), 2020.

211. El sistema de pensiones en Costa Rica: institucionalidad, gasto público y sostenibilidad financiera, José Francisco Pacheco, Hazel Elizondo y Juan Carlos Pacheco (LC/TS.2020/81), 2020.

210. El sistema de pensiones en México: institucionalidad, gasto público y sostenibilidad financiera, Héctor Villarreal y Alejandra Macías (LC/TS.2020/70), 2020.

209. El sistema de pensiones en El Salvador: institucionalidad, gasto público y sostenibilidad financiera, Carmelo Mesa-Lago y María Elena Rivera (LC/TS.2020/66), 2020.

208. El sistema de pensiones en la Argentina: institucionalidad, gasto público y sostenibilidad financiera, Oscar Cetrángolo y Carlos Grushka (LC/TS.2020/65), 2020.

207. El sistema de pensiones en el Perú: institucionalidad, gasto público y sostenibilidad financiera, Noelia Bernal Lobato (LC/TS.2020/64), 2020.

206. El sistema de pensiones en Colombia: institucionalidad, gasto público y sostenibilidad financiera, Francisco Azuero Zúñiga (LC/TS.2020/63), 2020.

205. El sistema de pensiones en Chile: institucionalidad, gasto público y sostenibilidad financiera, Andrea Bentancor (LC/TS.2020/61), 2020. 
